\title{
Triplet State Baird Aromaticity in Macrocycles: Scope, Limitations, and Complications
}

\author{
Published as part of The Journal of Physical Chemistry virtual special issue "Josef Michl Festschrift". \\ Rabia Ayub, Ouissam El Bakouri, Joshua R. Smith, Kjell Jorner, and Henrik Ottosson*
}

Cite This: J. Phys. Chem. A 2021, 125, 570-584

Read Online

\section{ACCESS |}

山lll Metrics \& More

回国 Article Recommendations

Supporting Information

ABSTRACT: The aromaticity of cyclic $4 n \pi$-electron molecules in their first $\pi \pi^{*}$ triplet state $\left(\mathrm{T}_{1}\right)$, labeled Baird aromaticity, has gained growing attention in the past decade. Here we explore computationally the limitations of $\mathrm{T}_{1}$ state Baird aromaticity in macrocyclic compounds, $[n]$ CM's, which are cyclic oligomers of four different monocycles ( $\mathrm{M}=p$-phenylene (PP), 2,5-linked furan (FU), 1,4-linked cyclohexa-1,3-diene (CHD), and 1,4-linked cyclopentadiene (CPD)). We strive for conclusions that are general for various DFT functionals, although for macrocycles with up to $20 \pi$-electrons in their main conjugation paths we find that for their $\mathrm{T}_{1}$ states single-point energies at both canonical

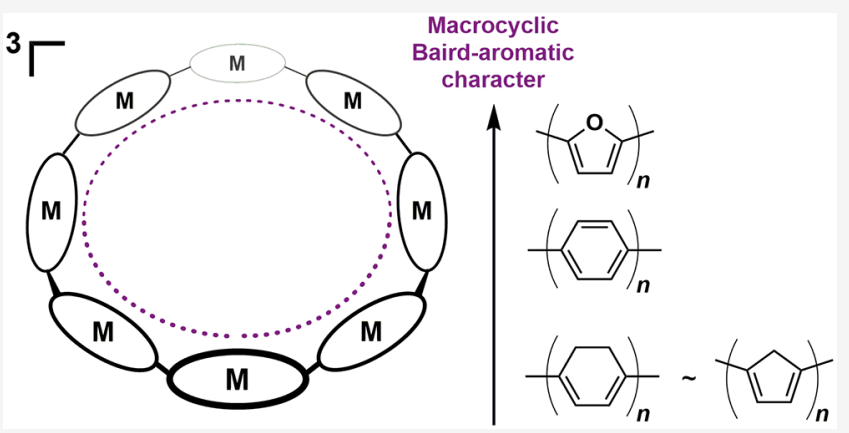
$\mathrm{UCCSD}(\mathrm{T})$ and approximative DLPNO-UCCSD(T) levels are

lowest when based on UB3LYP over UM06-2X and UCAM-B3LYP geometries. This finding is in contrast to what has earlier been observed for the electronic ground state of expanded porphyrins. Yet, irrespective of functional, macrocycles with 2,5-linked furans ( $[n]$ CFU's) retain Baird aromaticity until larger $n$ than those composed of the other three monocycles. Also, when based on geometric, electronic and energetic aspects of aromaticity, a ${ }^{3}[n]$ CFU with a specific $n$ is more strongly Baird-aromatic than the analogous ${ }^{3}[n]$ CPP while the magnetic indices tell the opposite. To construct large $\mathrm{T}_{1}$ state Baird-aromatic $[n]$ CM's, the design should be such that the $\mathrm{T}_{1}$ state Baird aromaticity of the macrocyclic perimeter dominates over a situation with local closed-shell Hückel aromaticity of one or a few monocycles and semilocalized triplet diradical character. Monomers with lower Hückel aromaticity in $S_{0}$ than benzene (e.g., furan) that do not impose steric congestion are preferred. Structural confinement imposed by, e.g., methylene bridges is also an approach to larger Baird-aromatic macrocycles. Finally, by using the Zilberg-Haas description of $\mathrm{T}_{1}$ state aromaticity, we reveal the analogy to the Hückel aromaticity of the corresponding closed-shell dications yet observe stronger Hückel aromaticity in the macrocyclic dications than Baird aromaticity in the $\mathrm{T}_{1}$ states of the neutral macrocycles.

\section{INTRODUCTION}

In recent years, it has become accepted that many compounds with $4 n \pi$-electron cycles are aromatic in their lowest electronically excited states, a characteristic now labeled as Baird aromaticity. ${ }^{1-19}$ Different types of compounds have been examined; monocyclic, polycyclic, heterocyclic and macrocyclic. Yet, the limitations and complications of the excited state Baird aromaticity concept need to be assessed in more detail so that we can avoid using it on molecules for which it is not applicable. A critical evaluation is also crucial for the successful and efficient implementation of Baird aromaticity in design of molecules with targeted properties, e.g., for applications in organic electronics or spintronics. Herein we explore macrocyclic compounds which are oligomers of four different monocyclic compounds; two of the monocycles used are Hückel-aromatic in their electronic ground states $\left(S_{0}\right)$ while the other two are nonaromatic with 1,3-diene segments. Our focus is on the potential $\mathrm{T}_{1}$ state Baird aromaticity of the macrocycles. What type of small monocycles as monomer units provide for strong Baird aromaticity in large macrocycles?

Peeks, Anderson and co-workers explored the potential excited-state Baird-aromatic and -antiaromatic characters of large $\pi$-conjugated porphyrin nanorings with 70-112 $\pi$ electrons in the main macrocyclic conjugation pathway (MCP), including both Hückel-antiaromatic $([4 n])$ and -aromatic $([4 n+2])$ cases. These nanorings are exceptional as they are composed of a series of Hückel-aromatic porphyrins linked via butadiynyl segments. Yet, it was observed that the extent of $\mathrm{T}_{1}$ state Baird aromaticity assessed through

Received: September 30, 2020

Revised: December 18, 2020

Published: January 11, 2021 
A
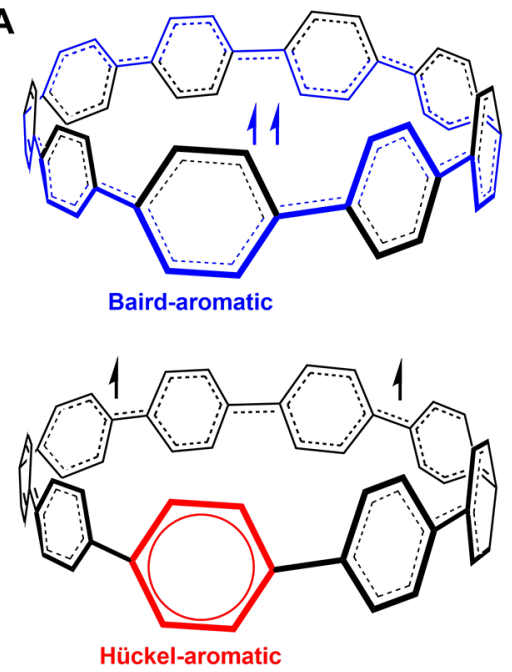

B

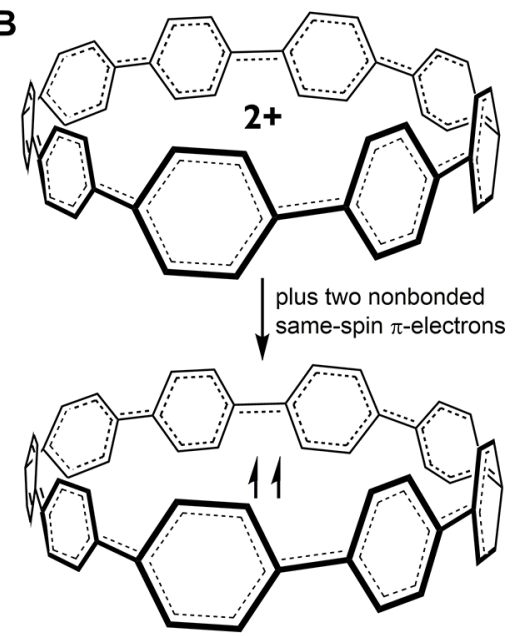

Figure 1. (A) Two (resonance) structures of ${ }^{3}[9]$ CPP, one representing macrocyclic Baird aromaticity and the other with a locally Hückelaromatic PP unit and with the triplet diradical distributed on the other eight PP units. (B) Conceptual formation of ${ }^{3}[9] \mathbf{C P P}$ from [9] $\mathbf{C P P}^{2+}$ by addition of two nonbonding same-spin $\pi$-electrons to [9] $\mathbf{C P P}^{2+}$, which has a Hückel-aromatic MCP with $4 \times 9-2($ i.e., $4 \times 8+2)$ spin-paired $\pi$ electrons.

computations varies strongly with choice of DFT functional. ${ }^{20}$ On the other hand, for $[n]$ cycloparaphenylene nanohoops ([n]CPP's $)^{21-24}$ in their $\mathrm{T}_{1}$ states it has been considered that long-range corrected functionals are preferred. ${ }^{25}$ When going to gradually larger $[n]$ CPP's in their $T_{1}$ states calculated with UCAM-B3LYP, structures changed from circular with fully delocalized triplet excitations to egg-shaped with the excitations localized to a subset of the $p$-phenylene units at $n$ $>5$.

Herein, we argue that in the $T_{1}$ state there is a tug-of-war between dominance of macrocyclic Baird-aromatic character of cyclic $4 n \pi$-electron MCP's and dominance of closed-shell Hückel-aromatic character of one or a few monocycles which forces the triplet diradical character to localize to a part of the macrocycle (Figure 1A). The outcome of this tug-of-war should vary with the type and size of a macrocycle and its monocyclic constituents; e.g., macrocyclic Baird aromaticity should be sustained more easily in $[n]$ cyclooligo(2,5-furan)s ([n]CFU) than in $[n]$ CPP's as the closed-shell Hückel aromaticity of furan is lower than that of benzene. ${ }^{26}$ Thus, one may argue that $[n]$ CFU's are better suited for macrocyclic Baird aromaticity than $[n]$ CPP's. Here it is notable that a $[n]$ CFU derivative has been synthesized and studied experimentally, ${ }^{27}$ and the parent $[n]$ CFU's have been explored through quantum chemical computations revealing that those with $n<8$ display planar or nearly planar $S_{0}$ state geometries and have electronic properties which make them interesting for organic electronics. ${ }^{28}$ The effect of heteroatoms on the $\mathrm{T}_{1}$ state Baird aromaticity of [6]CPP has been reported in a computational study where the phenylene units were changed successively to 1,4 -azaborines, ${ }^{29}$ a monocycle which is less Hückel-aromatic in $S_{0}$ than benzene. ${ }^{30}$ Yet, such replacements in the cases investigated led to attenuated Baird aromaticity according to nucleus independent chemical shifts (NICS's) calculated with the PBE0 functional. Can other heterocycles lead to increased Baird aromaticity?

An interesting description of Baird aromaticity is the description of Zilberg and Haas in which the $T_{1}$ state of a neutral $4 n \pi$-electron cycle is viewed as that of the corresponding Hückel-aromatic dication with $4 n-2$ spinpaired $\pi$-electrons plus two nonbonding same-spin $\pi$ electrons. $^{31}$ This description was utilized to rationalize the aromaticity/antiaromaticity switch that occurs when going from $S_{0}$ to $T_{1}$ in a [26]- and [28] porphyrinoid pair. ${ }^{13,32}$ Indeed, the potential Baird aromaticity of a neutral $[n]$ CPP in its $\mathrm{T}_{1}$ state could therefore closely resemble that of the corresponding $[n]$ CPP dication (Figure $1 \mathrm{~B}$ ), species for which in-plane Hückel aromaticity with $4 n-2 \pi$-electrons has been demonstrated. ${ }^{33}$ Yet, is the aromatic character stronger or weaker in the $\mathrm{T}_{1}$ state of $[n]$ CPP than in the closed-shell singlet state $[n] \mathbf{C P P}^{2+}$, or is it similar? Furthermore, is there a similarity to the dianions which are Hückel-aromatic with $4 n+$ $2 \pi$-electrons? The $[n]$ CPP dianions have been explored earlier, both experimentally and computationally, ${ }^{34-36}$ and are found to exhibit some aromaticity according to the computations. $^{34}$

Another issue is how to relate $[n]$ CPP and $[n]$ CFU with suitable large monocycles? As found by Beans, Fowler and Soncini for cyclic $\mathrm{C}_{16}$, cyclo[ $[4 n]$ carbons are interesting because their two orthogonally oriented $4 n \pi$-electron cycles allow them to be doubly Baird-aromatic in their lowest quintet states $\left(\mathrm{Qu}_{1}\right),^{37}$ in contrast to the $\mathrm{S}_{0}$ state where they are doubly Hückel-antiaromatic until a certain size. ${ }^{38-40}$ For the $T_{1}$ state, it was concluded that the out-of-plane $\pi$-conjugated path of $\mathrm{C}_{16}$ displayed Baird aromaticity while the in-plane path displayed Hückel antiaromaticity. A situation in the $T_{1}$ state with two similarly strong counteracting ring-currents, one diatropic (Baird-aromatic) and one paratropic (Hückelantiaromatic), could lead to a NICS value that corresponds to a nonaromatic situation. Indeed, such seemingly nonaromatic characters were recently observed from computations of cyclic $\mathrm{C}_{16}, \mathrm{C}_{20}$. and $\mathrm{C}_{24}{ }^{41}$ Furthermore, after the recent experimental generation of cyclo[18]carbon by Anderson and co-workers, $^{42,43}$ the aromaticity of cyclo $[4 n+2]$ carbons has gained increased attention, ${ }^{39,44}$ yet these are outside our explicit focus herein.

Now, if every 1,3-butadiyne unit in a cyclo[4n] carbon is replaced by monocycles contributing four $\pi$-electrons to the 
macrocyclic MCP (Figure 2) one arrives at a $[n]$ CPP with $n$ para-phenylene (PP) units and at a $[n]$ CFU with $n$ 2,5-linked

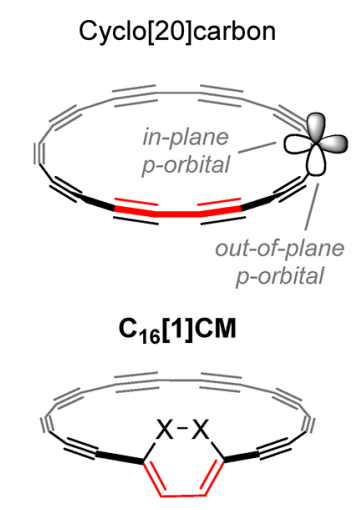

$\mathrm{X}-\mathrm{X}=\mathrm{CH}=\mathrm{CH}$ and $\mathrm{CH}_{2} \mathrm{CH}_{2}$

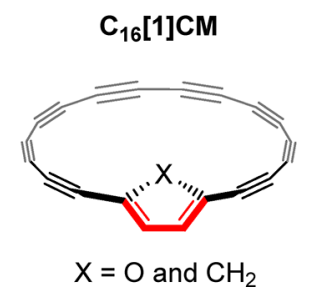

Figure 2. 1,3-Butadiyne segment in cyclic $\mathrm{C}_{20}$ and a monocyclic unit that participates with the same number of $\pi$-electrons in macrocyclic conjugation. Rings with $\mathrm{X}=\mathrm{O}$ and $\mathrm{CH}_{2}$ are named CFU and CCPD, respectively, and rings with $\mathrm{X}-\mathrm{X}=\mathrm{CH}=\mathrm{CH}$ and $\mathrm{CH}_{2} \mathrm{CH}_{2}$ are labeled as CPP and CCHD, respectively.

furan units (FU). How will the Baird aromaticity change upon this gradual transformation? It is noteworthy that the MCP involves in-plane orbitals in $[n]$ CPP while it involves out-ofplane orbitals in $[n]$ CFU's with $n<8$ (cf., trannulenes and annulenes, respectively).

As $[\mathbf{5}] \mathbf{C P P}$ is the smallest $[n] \mathbf{C P P}$ that has been synthesized and explored experimentally, ${ }^{45}$ we start our analysis at the $C_{20}$ cycle and replace one, two, or five 1,3-butadiyne segments with M units, reaching, e.g., [5]CPP. This $[n]$ CPP has the narrowest HOMO-LUMO gap among the $[n]$ CPP's synthesized and it has a benzenoid structure in its $\mathrm{S}_{0}$ state. ${ }^{33} \mathrm{~A}$ $\operatorname{NICS}(0)_{\text {iso }}$ value of $-1.3 \mathrm{ppm}$ in this state indicates a nonaromatic character with respect to the macrocyclic conjugation path. In our analysis we consider four different $\mathrm{M}$ units (Figure 2); the 1,4-linked benzene ( $p$-phenylene, PP), 1,4-linked cyclohexa-1,3-diene (CHD), 2,5-linked furan (FU), and 1,4-linked cyclopentadiene (CPD). The compounds are labeled as $\mathbf{C}_{20-4 n}[n] \mathbf{C M}$ with $\mathrm{M}$ as either PP, CPD, CHD, or FU, and $n$ as their number. The $[n]$ CCPD and $[n]$ CCHD are macrocycles with just single $4 n \pi$-electron paths and, accordingly, monocycles from an electronic perspective. In macrocycles with two $M$ units these were placed at maximal distance from each other.

A number of questions can now be posed: It is known that the extent of Baird aromaticity varies with computational method, $^{20}$ but how does it vary between the different macrocycles? Also, to what extent is there an agreement between various types of aromaticity indices on the magnitude of Baird aromaticity of macrocycles? Discrepancies between magnetic and electronic indices have earlier been highlighted, and it was concluded that (anti)aromaticity assessments exclusively based on the magnetic aspects are not justified. ${ }^{46}$ Furthermore, based on the Zilberg-Haas model ${ }^{31}$ one may ask how similar in aromatic character are the closed-shell $S_{0}$ state dications (e.g., $[n] \mathbf{C P P}^{2+}$ and $[n] \mathbf{C F u}^{2+}$ ) and the corresponding neutral triplet states? One may also consider the similarity to the corresponding $\mathrm{S}_{0}$ state dianions. The overarching goal of this study is to find routes to large macrocycles which to high probability are triplet state Baird-aromatic, not only in silico but also in reality.

\section{COMPUTATIONAL METHODS}

The $S_{0}$ and $T_{1}$ geometries were optimized using the B3LYP, ${ }^{47,48}$ M06-2X, ${ }^{49}$ and CAM-B3LYP ${ }^{50}$ functionals and the $6-311 G(d, p)$ basis set. ${ }^{51}$ Dispersion-corrected UB3LYP with Becke-Johnson damping (GD3BJ) ${ }^{52}$ was also computed in some cases. Relative energies were calculated using UDFT (B3LYP, M06-2X, and CAM-B3LYP) and coupled cluster with single and double substitutions and triple excitations with single point calculations at the various triplet UDFT geometries (UCCSD $(\mathrm{T}) / 6-311 \mathrm{G}(\mathrm{d}, \mathrm{p}) / / \mathrm{UDFT} / 6-311 \mathrm{G}-$ $(\mathrm{d}, \mathrm{p})) .{ }^{53,54}$ Canonical $\operatorname{CCSD}(\mathrm{T})$ was only computed for $\mathrm{C}_{8} \mathrm{H}_{8}, \mathrm{C}_{12} \mathrm{H}_{12}$ and $\mathrm{C}_{16} \mathrm{H}_{16}$. Domain pair natural orbitals (DLPNO) were employed in most of the $\operatorname{CCSD}(\mathrm{T})$ calculations (DLPNO-UCCSD $(\mathrm{T}) / \mathrm{cc}-\mathrm{pVTZ} / / \mathrm{UDFT} / 6-$ $311 \mathrm{G}(\mathrm{d}, \mathrm{p})) .{ }^{55-57}$ In the DLPNO-UCCSDT computations, cc-pVTZ was chosen as an auxiliary basis set. In the canonical $\operatorname{UCCSD}(\mathrm{T})$ and DLPNO-UCCSD $(\mathrm{T})$ calculations, three initial guesses were used, i.e., UHF, BLYP and ROHF. For $\mathrm{C}_{8} \mathrm{H}_{8}$ and $\mathrm{C}_{12} \mathrm{H}_{12}$, CASPT2/ANO-RCC-VDZP//UDFT/6$311 \mathrm{G}(\mathrm{d}, \mathrm{p})$ calculations were carried out using the atomic natural orbital (ANO-RCC-VDZP) basis set, while for $\mathrm{C}_{16} \mathrm{H}_{16}$ CASPT2/6-31G(d)//UDFT/6-311G(d,p) was instead used due to the large active space used. ${ }^{58-60}$ Regarding the latter computations, the active space used was 8 electrons in 8 orbitals (8in8), $12 \mathrm{in} 12$ and 16 in 16 for $\mathrm{C}_{8} \mathrm{H}_{8}, \mathrm{C}_{12} \mathrm{H}_{12}$, and $\mathrm{C}_{16} \mathrm{H}_{16}$, respectively. Most of the calculations (including the $\mathrm{T}_{1}$ diagnostic using the "T1diag" keyword) were performed with Gaussian 16 revision B.01 ${ }^{61}$ except for DLPNO-UCCSD $(T)$, fractional occupation number weighted density (FOD) ${ }^{62}$ and CASPT2 computations for which ORCA ${ }^{63}$ and OpenMolcas packages were used, ${ }^{60}$ respectively. Aromaticity was evaluated in terms of the nucleus independent chemical shift (NICS) ${ }^{64,65}$ with the GIAO method, ${ }^{66}$ ACID plots, ${ }^{67,68}$ the harmonic oscillator model of aromaticity (HOMA), ${ }^{69,70}$ the aromatic fluctuation index $(\mathrm{FLU})^{71}$ and isomerization stabilization energies (ISEs), ${ }^{72}$ computed at the B3LYP and M06-2X optimized geometries. ACID plots were computed using the software by Herges, ${ }^{67}$ HOMA was computed using Multiwfn ${ }^{73}$ and FLU was obtained with the ESI-3D program $^{74}$ and AIMAll. $^{75}$

\section{RESULTS AND DISCUSSION}

The investigation can be divided into two parts. The first and larger one provides an in-depth analysis of similarities, differences and trends among macrocycles with $20 \pi$-electron MCP's when based on different aromaticity indices (geometric, electronic, energetic, and magnetic) and functionals; how does the extent of $T_{1}$ state Baird aromaticity change when more $M$ units are incorporated into the $20 \pi$-electron path? The second part focuses on how the knowledge gained from the small macrocycles with $20 \pi$-electron paths can be utilized to 
understand larger macrocycles with potential $\mathrm{T}_{1}$ state Baird aromaticity. Yet, to assess which functional is preferred for the $\mathrm{T}_{1}$ states of the macrocycles investigated we first carried out single-point energy calculations with canonical $\operatorname{UCCSD}(\mathrm{T}) / 6$ $311 \mathrm{G}(\mathrm{d}, \mathrm{p}), \quad$ DLPNO-UCCSD $(\mathrm{T}) / \mathrm{cc}-\mathrm{pVTZ} \mathrm{Z}^{55,56}$ and CASPT2/ANO-RCC-VDZP using the $\mathrm{T}_{1}$ geometries at UB3LYP, ${ }^{47,48}$ UM06-2X, ${ }^{49}$ and UCAM-B3LYP ${ }^{50}$ levels. Still, as we strive for conclusions that are functional independent, the discussion is often based on results from more than one functional as this provides a broader base for conclusions on general trends and differences among the macrocycles.

Two idealized Baird-aromatic conformational types can be drawn for the $\mathbf{C}_{20-4 n}[n] \mathbf{C M}$ molecules in their $\mathrm{T}_{1}$ states; one with the $\mathrm{M}$ units lying in the plane of the macrocycle leading to an out-of-plane $\pi$-conjugated circuit and one with the monocycles arranged perpendicularly to the macrocycle plane so that the $\pi$-conjugated circuit runs in-plane. In the $T_{1}$ state, the macrocycles with $\mathrm{M}=\mathrm{PP}$ and $\mathrm{CHD}$ have the $\mathrm{M}$ units arranged perpendicularly to the plane of the macrocycle for each $n$, while those with $\mathrm{M}=\mathrm{FU}$ and CPD adopt essentially planar conformations, even though ${ }^{3}[5]$ CFU has a slightly bowl-shaped structure. Noteworthy, the compounds adopt the same conformational type in the $S_{0}$ and $T_{1}$ states (see Supporting Information).

Assessment of Computational Methods. Studies on $[4 n+2]$ annulenes and expanded porphyrins in their $S_{0}$ states have shown that functionals with a medium or low amount of HF exchange, such as B3LYP (20\%), tend to overstabilize bond-length equalized structures compared to coupled cluster calculations. ${ }^{76-80}$ Peeks, Anderson, and co-workers analyzed the effect of different density functionals on the triplet delocalization of porphyrin nanorings and found that the delocalization is sensitive to the computational method; functionals that normally overdelocalize gave larger NICS(0) values.

For expanded porphyrins in the $S_{0}$ state, functionals with higher amount of HF exchange, in particular M06-2X (54\%) and CAM-B3LYP (19-65\%), are in better agreement with geometries from canonical $\operatorname{CCSD}(\mathrm{T})$ and DLPNO-CCSD$(\mathrm{T})$, and the extent of aromaticity as measured by electronic indices is also lower with these functionals. ${ }^{76}$ As these results do not necessarily generalize to the $T_{1}$ state, we performed calculations of ${ }^{3} \mathrm{C}_{8} \mathrm{H}_{8},{ }^{3} \mathrm{C}_{12} \mathrm{H}_{12}$, and ${ }^{3} \mathrm{C}_{16} \mathrm{H}_{16}$ and also on ${ }^{3} \mathrm{C}_{16}[1] \mathrm{CPP},{ }^{3} \mathrm{C}_{12}[2] \mathrm{CPP},{ }^{3}[5] \mathrm{CPP},{ }^{3} \mathrm{C}_{16}[1] \mathrm{CFU}$, ${ }^{3} \mathrm{C}_{12}[\mathbf{2}] \mathrm{CFU}$, and ${ }^{3}[\mathbf{5}] \mathrm{CFU}$. Each of these species adopted just one stable conformer with each of the three functionals, also for the two [5]CM's. We applied both canonical $\mathrm{UCCSD}(\mathrm{T})$ and the DLPNO-UCCSD $(\mathrm{T})$. Due to large spin contamination of some compounds in $\mathrm{T}_{1}$ with UHF, we opted to use both a restricted open-shell HF (ROHF) reference and a UBLYP DFT reference wave function for the UCCSD $(\mathrm{T})$ calculation. These two references give no (ROHF) or only minute (UBLYP) spin contamination. The $T_{1}$ diagnostics values were in the range $0.011-0.031$ (Table S4), and varying with the geometry used (UB3LYP, UM06-2X, or UCAMB3LYP), they increased in the order UB3LYP $<$ UM06-2X < UCAM-B3LYP. The values were also consistently lower in CCSD calculations with the ROHF reference wave function. The fractional occupation number weighted density (FOD) ${ }^{62}$ values reveal that the multiconfigurational character in the $T_{1}$ state is highest in cyclic $\mathrm{C}_{20}$ (Tables S5 - S6), and that it decreased with number of $\mathrm{M}$ units in ${ }^{3} \mathrm{C}_{\mathbf{2 0}-4 n}[n] \mathbf{C M}$. For this reason, we disregard cyclic $\mathrm{C}_{20}$ hereafter. Finally, for
${ }^{3} \mathrm{C}_{16}[1] \mathrm{CPP},{ }^{3} \mathrm{C}_{16}[1] \mathrm{CFU}$ and the three $[4 n]$ annulenes in $\mathrm{T}_{1}$, we applied CASPT2//UDFT.

For the $[4 n]$ annulenes in their $\mathrm{T}_{1}$ states, the lowest coupled cluster energies are generally found when the calculations are carried out on UB3LYP optimized geometries, followed by UM06-2X optimized geometries. This trend is found at both canonical UCCSD $(\mathrm{T})$ and DLPNO-UCCSD(T) levels (Tables 1 and 2), and it is supported by results at CASPT2/

Table 1. Relative Energies at Canonical UCCSD $(T) / 6$ $311 G(d, p) / / U D F T / 6-311 G(d, p)$ (Normal Print) and CASPT2/ANO-RCC-VDZP//UDFT/6-311G(d,p) (Italics) Level with UB3LYP, UM06-2X, and UCAM-B3LYP Geometries $^{a}$

\begin{tabular}{clll} 
geometries & B3LYP & CAM-B3LYP & \multicolumn{1}{c}{ M06-2X } \\
${ }^{3} \mathrm{C}_{8} \mathrm{H}_{8}$ & $0.0,0.0$ & $0.8,0.4$ & $0.4,0.2$ \\
${ }^{3} \mathrm{C}_{12} \mathrm{H}_{12}$ & $0.0,0.0$ & $(4.4)^{b}, 1.5$ & $(4.4)^{b}, 0.0$ \\
${ }^{3} \mathrm{C}_{16} \mathrm{H}_{16}$ & $0.0,0.0^{c}$ & $(7.6)^{b}, 2.4^{c}$ & $1.4,0.9^{c}$
\end{tabular}

${ }^{a} \mathrm{UHF}$ reference wavefunction in $\operatorname{UCCSD}(\mathrm{T})$ calculation. Relative energies in $\mathrm{kcal} / \mathrm{mol}$. ${ }^{b}$ Values in parentheses are results for which the spin contamination in the reference exceeds $20 \%$, as seen in Table S5. ${ }^{c}$ CASPT2 calculations for ${ }^{3} \mathrm{C}_{16} \mathrm{H}_{16}$ run with the $6-31 \mathrm{G}(\mathrm{d})$ basis set.

ANO-RCC-VDZP//UDFT/6-311G(d,p) level (Table 1). However, the UB3LYP geometry of $\mathrm{C}_{16} \mathrm{H}_{16}$ gives the lowest $\mathrm{UCCSD}(\mathrm{T})$ energy with an ROHF initial guess while the UM06-2X geometry gives the lowest energy with a UBLYP guess. For ${ }^{3} \mathbf{C}_{16}[1]$ CFU and ${ }^{3} \mathbf{C}_{12}$ [2] CFU, UB3LYP geometries lead to the lowest coupled cluster energies regardless of initial guess, while for ${ }^{3} \mathrm{C}_{16}[1]$ CPP and ${ }^{3} \mathrm{C}_{12}[2] \mathrm{CPP}$ it depends on the choice of guess (ROHF or UBLYP). For ${ }^{3}[5]$ CPP and ${ }^{3}$ [5]CFU, DLPNO-UCCSD $(\mathrm{T})$ calculations still provisionally indicate that the UB3LYP geometry is the best, but for these species, the calculations had to be done with a small basis set. A caveat here is the observation that only one conformer each exist for the two [5]CM's, also with UCAM-B3LYP. For the larger $[n]$ CPP's, several conformers can exist and our conclusions on method preference are therefore not fully unambiguous as we were unable to carry out DLPNO$\mathrm{UCCSD}(\mathrm{T})$ calculations on these.

Noteworthy, DLPNO-CCSD $(\mathrm{T})$ calculations of systems with multireference character should be carried out with the TightPNO keyword. ${ }^{81}$ Such calculations for ${ }^{3} \mathrm{C}_{\mathbf{1 6}}[\mathbf{1}] \mathrm{CFU}$ and ${ }^{3} \mathrm{C}_{16}[\mathbf{1}] \mathrm{CPP}$, the two species with the highest $\mathrm{T}_{1}$ diagnostics and FOD values (Table S6), give relative energies which differ by up to $2.2 \mathrm{kcal} / \mathrm{mol}$ from the default DLPNO-CCSD $(\mathrm{T})$ results, yet, always in the direction favoring coupled cluster energies based on the B3LYP geometries. This finding is corroborated by results on the two compounds at CASPT2// UDFT level as the UB3LYP $\mathrm{T}_{1}$ geometries again lead to the lowest energies (Table S7). Thus, UB3LYP on average performs best, followed by UM06-2X, while UCAM-B3LYP performs worst. Yet, as indicated above we base our conclusions in the following on at least two functionals despite the provisional preference for UB3LYP.

The differences between the $\mathrm{T}_{1}$ geometries of the compounds at UB3LYP and UM06-2X levels are significant as the CC bond lengths differ by up to $0.081 \AA$ and on average by $0.015 \AA$ (see Figure S2 and S5). They differ on average even more between UB3LYP and UCAM-B3LYP (0.021 $\AA$ ), although the maximal difference is smaller (0.051 $\AA$ ). For 
Table 2. Relative DLPNO-UCCSD $(\mathrm{T}) / \mathrm{cc}-\mathrm{pVTZ}$ Energies (in kcal/mol) in $\mathrm{T}_{1}$ State at Geometries Optimized with UB3LYP, UCAM-B3LYP, and UM06-2X and with UBLYP and ROHF Reference Wavefunctions (ref. wfn.)

\begin{tabular}{|c|c|c|c|c|c|c|}
\hline ref. wfn. & BLYP & & & $\mathrm{ROHF}$ & & \\
\hline geometry & B3LYP & CAM-B3LYP & M06-2X & B3LYP & CAM-B3LYP & M06-2X \\
\hline${ }^{3} \mathrm{C}_{8} \mathrm{H}_{8}$ & 0.0 & 0.3 & 0.1 & 0.0 & 0.3 & 0.1 \\
\hline${ }^{3} \mathrm{C}_{12} \mathrm{H}_{12}$ & 0.0 & 1.1 & 0.2 & 0.0 & 1.6 & 1.0 \\
\hline${ }^{3} \mathrm{C}_{16} \mathrm{H}_{16}$ & 0.0 & 0.3 & -0.2 & 0.0 & 4.2 & 3.7 \\
\hline${ }^{3} \mathrm{C}_{16}[1] \mathrm{CFU}$ & $0.0,0.0^{a}$ & $7.3,6.7^{a}$ & $0.5,1.3^{a}$ & $0.0,0.0^{a}$ & $10.2,9.4^{a}$ & $0.3,1.4^{a}$ \\
\hline${ }^{3} \mathrm{C}_{12}[2] \mathrm{CFU}$ & 0.0 & 2.1 & 0.6 & 0.0 & 1.6 & 5.0 \\
\hline${ }^{3}[5] \mathrm{CFU}$ & $0.0^{b}$ & $1.4^{b}$ & $0.8^{b}$ & $0.0^{b}$ & $3.2^{b}$ & $2.8^{b}$ \\
\hline${ }^{3} \mathrm{C}_{16}[1] \mathrm{CPP}$ & $0.0,0.0^{a}$ & $0.6,2.8^{a}$ & $-0.6,0.0^{a}$ & $0.0,0.0^{a}$ & $0.6,2.5^{a}$ & $-0.5,0.0^{a}$ \\
\hline${ }^{3} \mathrm{C}_{12}[2] \mathrm{CPP}$ & 0.0 & -1.5 & -2.3 & 0.0 & 2.4 & 1.4 \\
\hline${ }^{3}[5] \mathrm{CPP}$ & $0.0^{b}$ & $2.6^{b}$ & $0.7^{b}$ & $0.0^{b}$ & $6.0^{b}$ & $2.7^{b}$ \\
\hline
\end{tabular}

${ }^{a}$ Relative energies obtained when using the TightPNO keyword in the DLPNO-UCCSD(T) calculations. ${ }^{b}$ Calculations with the cc-pVDZ basis set.

Table 3. Perimetric HOMA Values, $\Lambda(\mathrm{C}-\mathrm{C}-\mathrm{C}-\mathrm{C})$ Dihedral Angle Ranges, and Average Differences in $\Lambda(\mathrm{C}-\mathrm{C}-\mathrm{C}-\mathrm{C})$ between the $S_{0}$ and $T_{1}$ States at (U)B3LYP (Normal Print), (U)M06-2X (italics), and (U)CAM-B3LYP (Parentheses) Levels

\begin{tabular}{|c|c|c|c|c|c|c|}
\hline \multirow[b]{2}{*}{ compound } & \multicolumn{2}{|c|}{ HOMA } & \multirow[b]{2}{*}{$\Delta \operatorname{HOMA}\left(\mathrm{T}_{1}-\mathrm{S}_{0}\right)$} & \multicolumn{2}{|c|}{$\Lambda(\mathrm{C}-\mathrm{C}-\mathrm{C}-\mathrm{C})$ range } & \multirow[b]{2}{*}{$\Delta \Lambda_{\text {avg }}\left(\mathrm{C}-\mathrm{C}-\mathrm{C}-\mathrm{C} ; \mathrm{T}_{1}-\mathrm{S}_{0}\right)$} \\
\hline & $\overline{S_{0}}$ & $\overline{\mathrm{T}_{1}}$ & & $\mathrm{~S}_{0}$ & $\mathrm{~T}_{1}$ & \\
\hline$[5] \mathrm{CPP}$ & $\begin{array}{l}0.183,0.248 \\
\quad(0.255)\end{array}$ & $\begin{array}{l}0.535,0.529 \\
(0.443)\end{array}$ & $\begin{array}{l}0.352,0.287 \\
\quad(0.188)\end{array}$ & $\begin{array}{l}6.3-25.2,10.3-25.3 \\
\quad(4.2-26.8)\end{array}$ & $0.0,1.3-9.3(0.9-12.5)$ & $-16.7,-14.6(-9.8)$ \\
\hline$[5] \mathrm{CCHD}$ & $\begin{array}{l}0.492,0.247 \\
\quad(0.246)\end{array}$ & $\begin{array}{l}0.628,0.347 \\
\quad(0.315)\end{array}$ & $\begin{array}{l}0.136,0.100 \\
\quad(0.069)\end{array}$ & $\begin{array}{l}0.6-11.3,0.4-17.9(0.4- \\
12.9)\end{array}$ & $\begin{array}{l}0.6-12.0,0.7-15.6(0.5- \\
\quad 17.1)\end{array}$ & $-3.2,-5.4(-3.1)$ \\
\hline$[5] \mathrm{CFU}$ & $\begin{array}{l}0.485,0.393 \\
\quad(0.423)\end{array}$ & $\begin{array}{l}0.900,0.833 \\
\quad(0.749)\end{array}$ & $\begin{array}{l}0.415,0.440 \\
\quad(0.326)\end{array}$ & $0.0,0.1-0.5(0.2-8.9)$ & $0.0,0.8-8.9(0.8-13.9)$ & $0.0,6.5(4.9)$ \\
\hline$[5] \mathrm{CCPD}$ & $\begin{array}{l}0.388,0.125 \\
\quad(0.135)\end{array}$ & $\begin{array}{l}0.552,0.276 \\
(0.279)\end{array}$ & $\begin{array}{l}0.164,0.151 \\
\quad(0.144)\end{array}$ & $\begin{array}{l}0.0-27.9,0.0-35.4(0.0- \\
34.3)\end{array}$ & $\begin{array}{l}0.0-18.9,0.0-29.1(0.0- \\
26.5)\end{array}$ & $-13.5,-14.3(-14.6)$ \\
\hline
\end{tabular}

the $[4 n]$ annulenes in their $\mathrm{T}_{1}$ states, the bond length alternations is smallest with UB3LYP and largest with UCAM-B3LYP (Tables S3 and S6), in line with the observation by Matito and co-workers. ${ }^{82}$ Here it can be noted that spin delocalization has earlier been observed experimentally in porphyrin nanorings by ENDOR spectroscopy, ${ }^{83}$ in line with the UB3LYP result. Yet, the time scale of the EPR measurements (up to $2 \mu \mathrm{s}$ ) may not capture the situation with a rapid interconversion between conformers with semilocalized spin densities.

Another aspect of relevance for the computational method choice is the presence of repulsive $\mathrm{H}-\mathrm{H}$ interactions between adjacent $M$ units and the potential need for dispersioncorrected DFT. However, through a comparison of geometries calculated with and without Grimme's dispersion correction, ${ }^{84}$ we find that the effects are only modest and that they do not alter the results significantly (see Supporting Information).

Geometrical Impacts of Macrocyclic Baird Aromaticity. A high degree of aromaticity normally goes with highly symmetric structures. Thus, one can expect that ${ }^{3}[5] \mathbf{C M}$ macrocycles with marked Baird aromaticity in their $\mathrm{T}_{1}$ states possess $D_{n h}$ or $C_{n v}$ symmetry (or nearly so), whereby each monocycle in the macrocycle is structurally equivalent. A Baird-aromatic character should also result in bond length equalization along the $\mathrm{CC}$ bonds in the perimeter. To probe this we applied the geometry-based HOMA index, ${ }^{70}$ although it should be noted that it can only be applied for the perimeters in the full $[n] \mathbf{C M}$ 's as it will severely underestimate the $\mathrm{T}_{1}$ aromatic character of species with polyynic segments. Additionally, one monocycle (furan) is known to be a difficult case for HOMA. ${ }^{85}$ For these reasons, we also estimated the impact of $\mathrm{T}_{1}$ state Baird aromaticity from geometrical parameters that function as approximate indicators.

The HOMA values for the all-carbon perimeters in the [5]CM's in their $S_{0}$ states are low, corresponding to nonaromatic situations (Table 3 ). Yet, they increase in the $\mathrm{T}_{1}$ states with each of the three functionals with the largest increase $\left(\triangle \mathrm{HOMA}\left(\mathrm{T}_{1}-\mathrm{S}_{0}\right)\right)$ in [5] CFU leading to HOMA values $(0.75-0.90)$ that unambiguously correspond to macrocyclic Baird aromaticity. Noteworthy, despite that ${ }^{3}[\mathbf{5}] \mathbf{C F U}$ with UM06-2X and UCAM-B3LYP lacks symmetry it is still highly aromatic according to HOMA. The increases in the perimetric HOMA values upon excitation to $\mathrm{T}_{1}$ are also significant in [5] CPP, but for this compound the actual values in $\mathrm{T}_{1}$ are significantly lower $(0.44-0.53)$ than for ${ }^{3}[5] \mathbf{C F U}$, and correspond to weaker Baird aromaticity or nonaromaticity. In contrast, the $\triangle H O M A\left(\mathrm{~T}_{1}-\mathrm{S}_{0}\right)$ for $[5] \mathbf{C C H D}$ and [5]CCPD are more modest, although with UB3LYP they both have higher HOMA values in their $\mathrm{T}_{1}$ states than [5]CPP.

The geometrical impact of $\mathrm{T}_{1}$ state Baird aromaticity is also visible in several other geometric parameters, particularly if one considers the geometric changes when going from $S_{0}$ to $T_{1}$. One such parameter, the $\mathrm{C}-\mathrm{C}-\mathrm{C}-\mathrm{C}$ dihedral angle between adjacent monomer units $(\Lambda(\mathrm{C}-\mathrm{C}-\mathrm{C}-\mathrm{C}))$ in ${ }^{3}[\mathbf{5}] \mathbf{C M}$ 's, should decrease upon excitation for systems that adopt Baird aromaticity. Indeed, when going from $S_{0}$ to $T_{1}$ the average $\Lambda(\mathrm{C}-\mathrm{C}-\mathrm{C}-\mathrm{C})$ angles of ${ }^{3}[5] \mathrm{CPP},{ }^{3}[5] \mathrm{CCPD}$, and ${ }^{3}[5]$ CCHD decrease at all three DFT levels, indicative of attainment of some macrocyclic conjugation in the $\mathrm{T}_{1}$ state. However, for [5] CFU, this angle is already small in $S_{0}$, and there is therefore either no change or only a slight increase upon excitation to $\mathrm{T}_{1}$. Another useful geometrical parameter is 
Table 4. Approximate HOMA Values $\left(\mathrm{HOMA}_{\mathrm{appr}}\right)$ of the Diene Units of the Monocycles of $\mathrm{C}_{20-4 n}[n] \mathrm{CM}^{\prime} \mathrm{s}$ in the $\mathrm{S}_{0}$ and $\mathrm{T}_{1}$ States $^{a}$

\begin{tabular}{|c|c|c|c|}
\hline \multirow[b]{2}{*}{ compound } & \multicolumn{3}{|c|}{$\mathrm{HOMA}_{\mathrm{appr}}{ }^{b}$} \\
\hline & $\mathrm{S}_{0}$ & $\mathrm{~T}_{1}$ & $\Delta \operatorname{HOMA}\left(\mathrm{T}_{1}-\mathrm{S}_{0}\right)$ \\
\hline $\mathrm{C}_{16}[1] \mathrm{CPP}$ & $0.924,0.965,(0.975)$ & $0.803,0.917,(0.953)$ & $-0.121,-0.048(-0.022)$ \\
\hline $\mathrm{C}_{12}[2] \mathrm{CPP}$ & $0.924,0.965,(0.976)$ & $0.636,0.917,0.098(0.953,0.118)$ & $-0.288,-^{c}(-)^{c}$ \\
\hline $\mathrm{C}_{16}[1] \mathrm{CCHD}$ & $0.624,0.739,(0.406)$ & $0.451,0.054,(-0.007)$ & $-0.173,-0.685(-0.413)$ \\
\hline $\mathrm{C}_{12}[2] \mathrm{CCHD}$ & $0.618,0.404,(0.395)$ & $0.721,0.556,0.039,(-0.021,0.503)$ & $0.103,-^{c}(-)^{c}$ \\
\hline $\mathrm{C}_{16}[1] \mathrm{CFU}$ & $0.891,0.833,(0.823)$ & $0.960,0.985,(0.933)$ & $0.069,0.152,(0.110)$ \\
\hline $\mathrm{C}_{12}[2] \mathrm{CFU}$ & $0.876,0.814,(0.804)$ & $0.931,0.871,(0.934,0.494)$ & $0.055,0.057,(-)^{c}$ \\
\hline $\mathrm{C}_{16}[1] \mathrm{CCPD}$ & $0.515,0.355,(0.344)$ & $0.844,0.213,(0.064)$ & $0.329,-0.142(-0.280)$ \\
\hline $\mathrm{C}_{12}[2] \mathrm{CCPD}$ & $0.504,0.318,(0.332)$ & $0.925,0.469,0.157,(0.016,0.416)$ & $0.421,-^{c}(-)^{c}$ \\
\hline
\end{tabular}

${ }^{a}$ Results with (U)B3LYP (normal print), (U)M06-2X (italics), and (U)CAM-B3LYP (parentheses). ${ }^{b}$ The HOMA values determined for the diene segments in the monocycles that contribute to the macrocyclic Baird aromaticity. ${ }^{c}$ As the HOMA values differ for the different $\mathrm{M}$ units within the compound in its $\mathrm{T}_{1}$ state there is no distinct $\triangle \mathrm{HOMA}\left(\mathrm{T}_{1}-\mathrm{S}_{0}\right)$.

the length of the $\mathrm{C}-\mathrm{C}$ bonds between the monocycles as these bonds should shorten in Baird-aromatic macrocycles. The shortening in these bonds is apparent in both ${ }^{3}[\mathbf{5}]$ CPP and ${ }^{3}[\mathbf{5}]$ CFU with all three functionals (Table S8a), but it is only with (U)B3LYP that the shortening is of equal magnitude in the five $\mathrm{C}-\mathrm{C}$ bonds between the $\mathrm{M}$ units (the structures are not symmetric with the other functionals). Furthermore, with each of the three functionals these $\mathrm{C}-\mathrm{C}$ bonds are slightly shorter in ${ }^{3}[5]$ CFU than in ${ }^{3}[5]$ CPP (1.415 vs. $1.437 \AA$ with

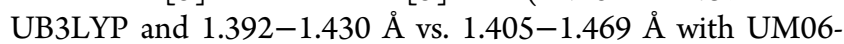
$2 \mathrm{X})$, indicating more distinct Baird-aromatic character in ${ }^{3}[5]$ CFU.

For the $\mathrm{C}_{16}[\mathbf{1}] \mathbf{C M}$ and $\mathbf{C}_{12}[2] \mathbf{C M}$ compounds, we examined approximate HOMA values $\left(\mathrm{HOMA}_{\text {appr }}\right)$ determined based on only the diene segments of the $M$ units that participate in the macrocyclic Baird aromaticity (Table 4). At the UB3LYP level, each ${ }^{3} \mathbf{C}_{16}[1] \mathbf{C M}$ and ${ }^{3} \mathbf{C}_{12}$ [2] CM is Bairdaromatic while with UCAM-B3LYP this is the case only for ${ }^{3} \mathrm{C}_{16}[1] \mathrm{CPP}$ and ${ }^{3} \mathrm{C}_{16}[1] \mathrm{CFU}$. Interestingly, when going from ${ }^{3} \mathrm{C}_{16}[\mathbf{1}] \mathrm{CM}$ to ${ }^{3} \mathrm{C}_{12}[2] \mathrm{CM}$ at UB3LYP level, one can note a significant weakening of the $\mathrm{T}_{1}$ Baird-aromatic character of ${ }^{3} \mathbf{C}_{12}$ [2] CM in the case when $\mathrm{M}=\mathrm{PP}$, a minute weakening when $\mathrm{M}=\mathrm{FU}$, and a strengthening when $\mathrm{M}=\mathrm{CPD}$ and $\mathrm{CHD}$. This suggests that $T_{1}$ state Baird-aromatic character is hampered by a higher proportion of PP units in a macrocycle. It can also be noted that when based on the $\mathrm{HOMA}_{\text {appr }}$ values at UB3LYP level, ${ }^{3} \mathbf{C}_{\mathbf{2 0}-4 n}[n]$ CFU ( $n=1$ and 2) display slightly higher Baird aromaticity than ${ }^{3} \mathrm{C}_{\mathbf{2 0 - 4 n}}[n] \mathrm{CPP}(n=1$ and 2$)$. Finally, the $\mathrm{C}-\mathrm{C}(\mathrm{M})$ bond lengths are shorter in ${ }^{3} \mathrm{C}_{16}[\mathbf{1}] \mathrm{CFU}$ and ${ }^{3} \mathbf{C}_{12}[2]$ CFU (1.376 and $1.371 \AA$ with UB3LYP) than in ${ }^{3} \mathrm{C}_{16}[\mathbf{1}] \mathrm{CPP}$ and ${ }^{3} \mathrm{C}_{12}[2] \mathrm{CPP}(1.401$ and $1.386 \AA$ ), revealing a stronger macrocyclic conjugation in the first compound class.

Electronic Impact of Macrocyclic Baird Aromaticity. In an idealized (strongly) Baird-aromatic cycle with a $D_{n \mathrm{~h}}$ or $C_{n \mathrm{v}}$ symmetric structure, the spin density distribution should be such that there is a continuous excess of $\alpha$-spin (or $\beta$-spin) density along the complete cycle. Excess of $\beta$-spin density at any atom(s) along the path may suggest a discontinuous (acyclic) distribution of the two unpaired $\alpha$-electrons of the triplet diradical, and consequently, a lowered or negligible Baird aromaticity. At UB3LYP level, this spin density criterion is satisfied by eight of the $1220-\pi$-electron macrocyclic compounds examined herein; the four exceptions are ${ }^{3}[5]$ CCPD and each of the three ${ }^{3} \mathbf{C}_{20-4 n}[n]$ CCHD's $(n=1$, 2 , or 5). Two of these compounds ( ${ }^{3}[5]$ CCPD and
${ }^{3}[5]$ CCHD) have geometries where the cyclic $\pi$-conjugation in the MCP is reduced or broken due to steric congestion between adjacent $M$ units while the other two have planar structures that nominally could provide strong Baird aromaticity, yet they are nonetheless nonaromatic. However, the functional has a decisive impact on the spin density distribution as seen for ${ }^{3}[5]$ CFU since the excess in $\alpha$-spin density gets interrupted by $\beta$-spin excess at points along the macrocycle when going from UB3LYP to UM06-2X and UCAM-B3LYP (Figure 3 ), and this also occurs for ${ }^{3}[5]$ CPP

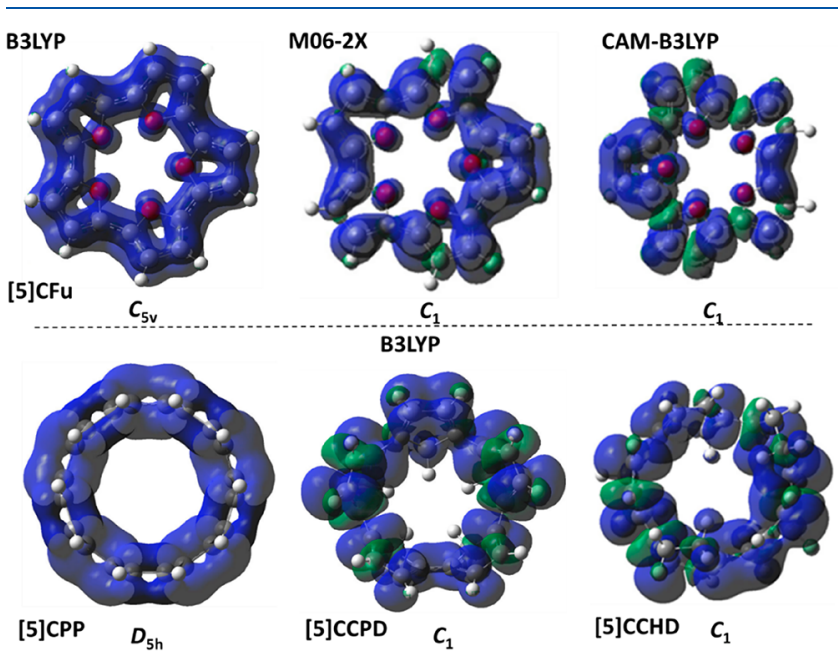

Figure 3. Spin densities of ${ }^{3}[5]$ CFU at UB3LYP, UM06-2X, and UCAM-B3LYP levels at the top row and ${ }^{3}[5]$ CPP, ${ }^{3}[5]$ CCPD, and ${ }^{3}[5]$ CCHD at UB3LYP level at the bottom row. The isodensity surface values in the plots are 0.0040 .

(Figure S9). Thus, a continuous and evenly distributed $\alpha$-spin excess around a complete cycle reveals idealized Baird aromaticity, although species with modest disruptions are still Baird-aromatic as seen for ${ }^{3}[5]$ CFU where the HOMA value is well above 0.5 with UCAM-B3LYP.

The extent of Baird aromaticity was also assessed through the electronic FLU index ${ }^{71}$ for the $[4 n]$ annulenes and in the perimeters of the $[\mathbf{5}] \mathbf{C M}$ macrocycles (Table 5). Compounds with polyyne segments were not considered as their FLU values deviate from the others due to their CC triple bonds. According to FLU all [ $4 n]$ annulenes are $\mathrm{T}_{1}$ Baird-aromatic at both the B3LYP and M06-2X levels. The differences between the FLU values in the $S_{0}$ and $T_{1}$ states decrease when going to 
Table 5. FLU Values of Compounds in Their $S_{0}$ and $T_{1}$ States at (U)B3LYP/6-311G(d,p) (Normal Print) and (U)M06-2X/6-311G(d,p) (Italics) Levels

\begin{tabular}{lccc} 
Compound & $\mathrm{S}_{0}$ & $\mathrm{~T}_{1}$ & $\Delta$ FLU $_{\mathrm{T} 1-\mathrm{S} 0}$ \\
$\mathrm{C}_{8} \mathrm{H}_{8}$ & $0.056,0.062$ & $0.001,0.001$ & $-0.055,-0.062$ \\
$\mathrm{C}_{12} \mathrm{H}_{12}$ & $0.042,0.051$ & $0.002,0.008$ & $-0.040,-0.043$ \\
$\mathrm{C}_{16} \mathrm{H}_{16}$ & $0.029,0.041$ & $0.002,0.006$ & $-0.027,-0.036$ \\
$\mathrm{C}_{20} \mathrm{H}_{20}$ & $0.023,0.034$ & $0.001,0.011$ & $-0.022,-0.023$ \\
{$[\mathbf{5}]$ CCHD } & $0.037,0.046$ & $0.015,0.026$ & $-0.023,-0.019$ \\
{$[\mathbf{5}]$ CCPD } & $0.036,0.046$ & $0.016,0.028$ & $-0.020,-0.018$ \\
{$[\mathbf{5}] \mathbf{C F U}$} & $0.018,0.022$ & $0.009,0.012$ & $-0.009,-0.009$ \\
{$[\mathbf{5}] \mathbf{C P P}$} & $0.017,0.016$ & $0.016,0.017$ & $-0.000,0.001$ \\
\hline
\end{tabular}

larger cycles but this is primarily a result of reductions in the values for the $S_{0}$ state when the annulenes become larger. In $\mathrm{T}_{1}$, the extent of aromaticity is more or less constant according to FLU at UB3LYP level while there is a variation with UM06$2 \mathrm{X}$ with ${ }^{3} \mathrm{C}_{8} \mathrm{H}_{8}$ as the most and ${ }^{3} \mathrm{C}_{20} \mathrm{H}_{20}$ as the least Bairdaromatic, in line with similar findings by Matito and coworkers on $[4 n]$ annulenes in their $\mathrm{T}_{1}$ states up until $\mathrm{C}_{16} \mathrm{H}_{16}{ }^{82}$

With regard to the ${ }^{3}[\mathbf{5}] \mathbf{C M}$ 's, the one with the most Bairdaromatic character according to FLU at both UB3LYP and UM06-2X levels is ${ }^{3}[5]$ CFU. With UM06-2X, the FLU value of this macrocycle is similar to that of ${ }^{3} \mathrm{C}_{20} \mathrm{H}_{20}$ while it is slightly less Baird-aromatic than the latter with UB3LYP. The other three ${ }^{3}[\mathbf{5}] \mathbf{C M}$ 's are somewhat less aromatic than ${ }^{3}[5]$ CFU at both levels.

Energy Impacts of Macrocyclic Baird Aromaticity. As an energy-based aromaticity index we applied isomerization stabilization energies (ISEs) in versions where the 1,3hydrogen shift(s) takes place at one single (di)methyl substituted $\mathrm{M}$ unit. The methyl/methylene groups are placed so that steric congestion is avoided on either side of the ISE reaction (Figure 4). For the compounds with PP monocycles we used dimethyl substitution at one PP unit as the macrocyclic conjugation otherwise cannot be broken.

For each M, and with both UB3LYP and UM06-2X, one can note gradually decreasing ISE values when $n$ increases in ${ }^{3} \mathbf{C}_{20-4 \mathrm{n}}[n] \mathbf{C M}(n=1,2$ or 5$)$, indicating reduced Baird

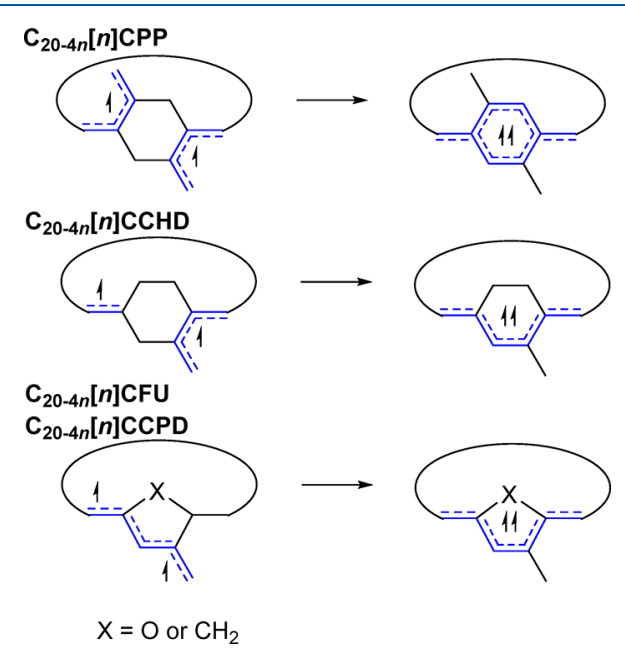

Figure 4. 1,3-Hydrogen shift reactions used to assess the isomerization stabilization energies (ISEs). Blue bonds represent $\pi$ conjugated segments: acyclic on the reactant side and cyclic (potentially Baird-aromatic) on the product side. aromaticity. For ${ }^{3}[5] \mathrm{CPP}$ and ${ }^{3}[5]$ CFU the ISE values are still negative, revealing stabilization upon formation of Bairdaromatic macrocycles in $\mathrm{T}_{1}$, but they are positive for ${ }^{3}[5]$ CCHD and ${ }^{3}[5]$ CCPD indicating a lack of aromatic stabilization. Also, the ISE values for ${ }^{3} \mathbf{C}_{20-4 n}[n]$ CFU's are always higher than those of the analogous ${ }^{3} \mathrm{C}_{20-4 n}[n]$ CPP. As a comparison, the ISE values of ${ }^{3} \mathrm{C}_{8} \mathrm{H}_{8}$ and ${ }^{3} \mathrm{C}_{20} \mathrm{H}_{20}$ at (U)B3LYP ((U)M06-2X) levels are $-16.9(-10.8)$ and $-19.1(-14.4) \mathrm{kcal} / \mathrm{mol}$, and for benzene in the $S_{0}$ state (the aromatic archetype), it is $-33.9(-34.2) \mathrm{kcal} / \mathrm{mol}$, resembling earlier computed ISE values for small aromatic monocycles in $\mathrm{T}_{1}$ and $\mathrm{S}_{0} \cdot{ }^{72,86,87}$ The $\mathrm{T}_{1}$ state aromatic stabilization in a polycyclic compound with a cyclooctatetraene core has also been determined experimentally as $21-22 \mathrm{kcal} /$ mol. ${ }^{14}$ Thus, the Baird-aromatic stabilization of ${ }^{3}[5]$ CPP is already low with UB3LYP, and with UM06-2X it is merely $23 \%$ of the ISE value of $S_{0}$ state benzene at the same level. For ${ }^{3}[5]$ CFU, on the other hand, the ISE values are essentially equal to those of triplet state $\mathrm{C}_{20} \mathrm{H}_{20}$ and approximately half the aromatic stabilization of benzene in $\mathrm{S}_{0}$. Hence, it is apparent at both UB3LYP and UM06-2X levels that the aromatic stabilization drops as the number of PP and FU units increase in a ${ }^{3} \mathbf{C}_{20-4 n}[n] \mathbf{C M}$. Yet, the results also suggest that a macrocycle ${ }^{3}[n] \mathbf{C M}$ composed of moderately Hückel-aromatic $\mathrm{M}$ units such as furans has a higher likeliness to sustain macrocyclic Baird aromaticity to larger sizes in its $T_{1}$ state. With UCAM-B3LYP the ISE values of ${ }^{3}[5]$ CPP and ${ }^{3}[5]$ CFU are -7.8 and $-12.5 \mathrm{kcal} / \mathrm{mol}$, respectively, resembling those at UM06-2X level (Table 6).

Table 6. Isomerization Stabilization Energies (ISE's) of $\mathrm{C}_{20-4 n}[n] \mathrm{CM}$ in Their $\mathrm{T}_{1}$ States at UB3LYP/6-311G(d,p) (Normal Print) and UM06-2X/6-311G(d,p) (Italics) Levels

\begin{tabular}{ccccc}
$n$ & PP & \multicolumn{1}{c}{ FU } & \multicolumn{1}{c}{ CPD } & \multicolumn{1}{c}{ CHD } \\
1 & $-22.9,-14.1$ & $-25.4,-22.3$ & $-14.2,-12.8$ & $-7.4,-4.4$ \\
2 & $-17.4,-10.3$ & $-24.3,-24.1$ & $-9.5,-1.2$ & $-7.3,-5.1$ \\
5 & $-13.1,-7.8$ & $-19.1,-14.2$ & $8.6,12.1$ & $8.1,12.5$ \\
\hline
\end{tabular}

Magnetic Aspects of Macrocyclic Baird Aromaticity. Magnetic aromaticity indices (NICS and induced current density maps) are the most frequently applied computational tools for aromaticity assessments. ${ }^{88}$ However, it has been pointed out that these indicators should not be used alone, ${ }^{46}$ and it has been shown that NICS can be an ambiguous measure of magnetically induced paratropic or diatropic ring currents in molecules. ${ }^{9}$ NICS values should therefore be combined with current density maps. Now, to what extent do the results of magnetic indices on potential Baird aromaticity in the present macrocycles differ from the results of other types of indices?

The ACID plots for the $T_{1}$ states, calculated with UB3LYP, reveal diatropic ring-currents along the perimeters of all except two macrocycles when going from ${ }^{3} \mathbf{C}_{16}[\mathbf{1}] \mathbf{C M}$ to ${ }^{3}[5] \mathbf{C M}$ (Figure 5 and Figures S8-S92), the exceptions being ${ }^{3}[5]$ CCPD and ${ }^{3}$ [5] CCHD. Slightly fewer macrocycles exhibit diatropic ring currents with UM06-2X as they are observed for ${ }^{3} \mathbf{C}_{20-4 n}[n]$ CFU and ${ }^{3} \mathbf{C}_{20-4 n}[n]$ CPP $(n=1,2$ and 5), and with UCAM-B3LYP only ${ }^{3} \mathbf{C}_{12}[2]$ CFU and ${ }^{3}[5]$ CFU exhibit such ring currents.

With regard to NICS, all ${ }^{3} \mathbf{C}_{20-4 n}[n] \mathbf{C M}(n=1,2$ or 5) with $\mathrm{M}=\mathrm{PP}$ or FU calculated with UB3LYP or UM06-2X show 


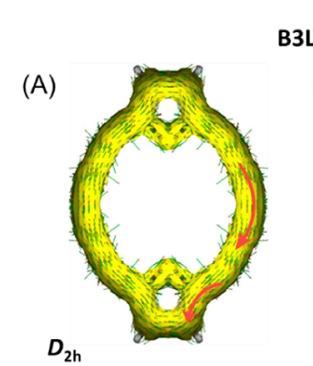

B3LYP
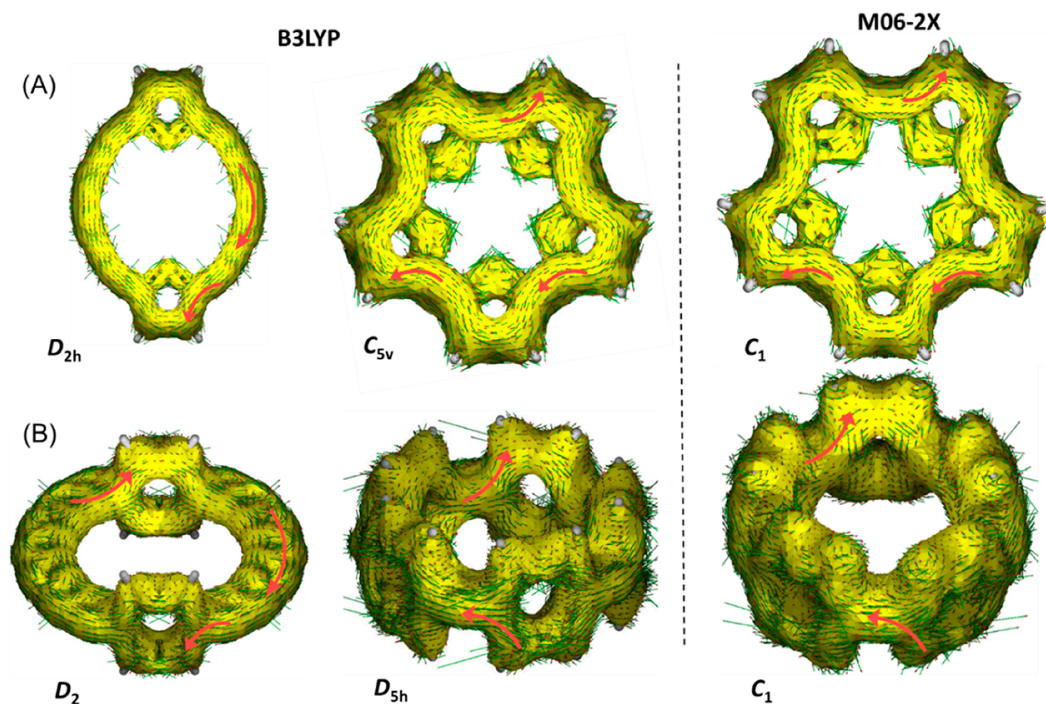

Figure 5. ACID plots of (A) ${ }^{3} \mathrm{C}_{20-4 n}[n] \mathrm{CFU}\left(n=2\right.$ and 5) and (B) ${ }^{3} \mathrm{C}_{20-4 n}[n] \mathrm{CPP}(n=2$ and 5) at UB3LYP/6-311+G(d,p) and UM06-2X/6$311+\mathrm{G}(\mathrm{d}, \mathrm{p})$ levels. For the ACID plots in the $\mathrm{S}_{0}$ state and all other compounds, see the Supporting Information.

moderately to highly negative $\operatorname{NICS}(0)_{z z}$ values (Table 7 ). Thus, the NICS results are in line with the induced diatropic

Table 7. NICS $(0)_{z z}$ Values of ${ }^{3} \mathrm{C}_{20-4 n}[n] \mathrm{CM}$ Compounds in Their $\mathrm{T}_{1}$ States at GIAO/UB3LYP/6-311+G(d,p) (Normal) and GIAO/UM06-2X/6-311+G(d,p) (Italics) Levels ${ }^{a}$

\begin{tabular}{ccccc}
$\begin{array}{c}n \text { of } \\
\text { CM } \\
\text { units }\end{array}$ & PP & FU & \multicolumn{1}{c}{ CPD } & CHD \\
1 & $-48.3,-33.8$ & $-34.5,-22.1$ & $-31.9,-10.2$ & $-28.5,-8.8$ \\
2 & $-49.9,-29.5$ & $-45.5,-41.7$ & $-42.9,-5.9$ & $-33.3,-8.4$ \\
5 & $-40.5,-28.3$ & $-31.6,-22.0$ & $-4.8,-3.2$ & $-8.2,0.5$ \\
${ }^{a} \mathrm{NICS}(0)_{\text {iso }}$ values found in Table S14. & & \\
\hline
\end{tabular}

ring currents displayed in the ACID plots. Similar as observed with the other indices, the NICS values from UM06-2X indicate slightly lower Baird aromaticity than those at UB3LYP level, except for the NICS of all macrocycles with $\mathrm{M}=\mathrm{CHD}$ and CPD where UM06-2X indicate lack of aromaticity. Such nonaromatic situations are even found with UB3LYP for ${ }^{3}[5]$ CCHD and ${ }^{3}[5]$ CCPD. In contrast, the $T_{1}$ aromatic character according to NICS is preserved in both ${ }^{3}[5]$ CPP and ${ }^{3}[5]$ CFU according to UB3LYP and UM06-2X while they are just modestly Baird-aromatic according to NICS at UCAMB3LYP level ( $\operatorname{NICS}(0)_{z z}=-11.3$ and $-7.4 \mathrm{ppm}$, respectively). Interestingly, the NICS values with all three functionals are more negative in ${ }^{3}[5]$ CPP than in ${ }^{3}[5]$ CFU. This ordering in relative degree of aromaticity is contrary to the findings made with the other index types. It is also noteworthy that the strongest aromatic character according to $\operatorname{NICS}(0)_{z z}$ is found for the ${ }^{3} \mathrm{C}_{12}[2] \mathrm{CM}$ species. There is a small attenuation when going to ${ }^{3}[\mathbf{5}] \mathbf{C P P}$ while ${ }^{3}[\mathbf{5}] \mathbf{C F U}$ is as aromatic as ${ }^{3} \mathrm{C}_{16}[1]$ CFU.

Taken together, the variations in Baird-aromatic character based on magnetic indicators follow largely the same trends as observed by the other indices, except for the opposite order in the extent of aromatic character of ${ }^{3} \mathrm{C}_{20-4 n}[n] \mathrm{CFU}$ vs. ${ }^{3} \mathrm{C}_{\mathbf{2 0}-4 n}[n]$ CPP when based on NICS values.

Synopsis of Results on ${ }^{3} \mathrm{C}_{20-4 n}[n] C M$ Macrocycles. Conclusions on three aspects can be made based on the computational results above: (i) on the extent of Baird aromaticity in the various ${ }^{3} \mathbf{C}_{\mathbf{2 0}-4 n}[n] \mathbf{C M}$ species, (ii) on the (dis)similarities in the aromaticity assessments based on the various indices, and (iii) on the differences between the three functionals used. Starting with the last aspect, as already reported, $^{20}$ there is a distinct variation between different functionals to what extent they describe large (macro)cycles as Baird-aromatic. CAM-B3LYP strongly disfavors Baird aromaticity, yet based on this feature, one may also single out which macrocycles with high certainty are Baird-aromatic in reality. On the other hand, our coupled cluster computations indicate that the UB3LYP geometries are the best for the species studied herein. With regard to the aromaticity indices, they report essentially similar trends between the various ${ }^{3} \mathbf{C}_{20-4 n}[n] \mathbf{C M}$ compounds, except for NICS indicating that the Baird aromaticity in ${ }^{3} \mathrm{C}_{20-4 n}[n]$ CPP's to be more markedly Baird-aromatic than the Baird-aromatic ${ }^{3} \mathrm{C}_{20-4 n}[n]$ CFU's.

Finally, with regard to the first aspect listed above, ${ }^{3}[5]$ CFU has a highly Baird-aromatic character according to all aromaticity indices applied herein and according to two of the three functionals applied. Furthermore, the attenuation in Baird-aromatic character when going from ${ }^{3} \mathrm{C}_{16}-[1] \mathrm{CM}$ to ${ }^{3}[5] \mathrm{CM}$ is smallest when $\mathrm{M}=\mathrm{FU}$ indicating that this unit is suitable for designing larger $[n] \mathbf{C M}$ macrocycles. In contrast, the $[n]$ CPP's seem not to be optimal if one seeks macrocycles with strong $\mathrm{T}_{1}$ state Baird aromaticity, unless further tailored.

$\mathrm{T}_{1}$ State Baird Aromaticity of Larger and Altered [n]CMs. We now focus on larger ${ }^{3}[n]$ CPP and ${ }^{3}[n]$ CFU $(n>$ 5 ), and their derivatives, in order to assess at what sizes $n$ these macrocycles cease to be Baird-aromatic. The ${ }^{3}[n]$ CFU's are particularly promising as ${ }^{3}[\mathbf{5}] \mathbf{C F U}$ was Baird-aromatic even with UCAM-B3LYP, in contrast to ${ }^{3}$ [5]CPP. Conversely, since ${ }^{3}[5]$ CCPD and ${ }^{3}[5]$ CCHD are nonaromatic even with UB3LYP, larger ${ }^{3}[n]$ CCPD's and ${ }^{3}[n]$ CCHD's with $n>5$ are not further considered. For macrocycles for which we found Baird-aromatic minima we have checked for nonaromatic minima by starting from several different geometries that were markedly distorted.

According to UCAM-B3LYP, the ${ }^{3}[n]$ CPP's with $n>5$ have egg-shaped structures which are nonaromatic, ${ }^{25}$ and similar attenuations of the Baird aromaticity occur also with UB3LYP 
Table 8. HOMA, NICS $(0)_{z z}$, and FLU Values for ${ }^{3}[n] \mathrm{CM}(\mathrm{M}=\mathrm{PP}$ or FU, $n=6-8)$ and at UB3LYP/6-311G(d,p) (Normal Print) and UM06-2X/6-311G(d,p) (Italics) Levels

\begin{tabular}{clc} 
compound & \multicolumn{1}{c}{ sym } & HOMA T $_{1}$ \\
${ }^{3}[6]$ CPP & $C_{2 h}, C_{1}$ & $0.588,0.424$ \\
${ }^{3}[7]$ CPP & $C_{1}, C_{2}$ & $0.504,0.407$ \\
${ }^{3}[8]$ CPP & $C_{1}, C_{1}$ & $0.457,0.403$ \\
${ }^{3}[6]$ CFU & $C_{6 v}, C_{6 v}$ & $0.949,0.858$ \\
${ }^{3}[7]$ CFU & $D_{7 h}, D_{7 h}$ & $0.969,0.841$ \\
${ }^{3}[8]$ CFU & $D_{8 h}, C_{1}$ & $0.974,0.808$
\end{tabular}

$\begin{array}{lc}\operatorname{NICS}(0)_{z z} \mathrm{~T}_{1} & \mathrm{FLU} \mathrm{T}_{1} \\ -41.3,-8.6 & 0.0150,0.0184 \\ -15.1,-6.2 & 0.0163,0.0183 \\ -4.7,-5.8 & 0.0169,0.0181 \\ -33.1,-16.6 & 0.0088,0.0122 \\ -36.3,-10.3 & 0.0085,0.0131 \\ -38.2,-3.2 & 0.0084,0.0143\end{array}$

and UM06-2X but at higher $n$. The distortion to nonaromatic ${ }^{3}[n]$ CPP's is complete at $n=8$ with UB3LYP and at $n=6$ or 7 with UM06-2X, seen both with NICS and HOMA (Tables 8, S17, and S18). Yet the FLU values, in contrast to NICS and HOMA, reveal no significant weakening of the electron delocalization in the ${ }^{3}[n]$ CPP's when going from $n=6$ to $n$ = 8; neither with B3LYP nor M06-2X. That is, also the unsymmetric ${ }^{3}[8]$ CPP has FLU values that correspond to Baird aromaticity with both functionals despite that the interring $\Lambda \mathrm{C}-\mathrm{C}-\mathrm{C}-\mathrm{C}$ angles are found in the ranges $2.2-29.2^{\circ}$ (UB3LYP) and $6.9-35.7^{\circ}$ (UM06-2X), and with several dihedral angles larger than $20^{\circ}$ (four angles with UB3LYP and six angles with UM06-2X). Additionally, the delocalization index (DI), on which FLU depends, also does not help to explain the incongruencies between this electronic index, on the one side, and NICS and HOMA on the other. By taking the mean of the DI of all bonds that participate in the circuit, no significant variation is observed when going to larger macrocycles (the mean DI $=1.296,1.297$, and 1.299 e for ${ }^{3}[6] \mathrm{CPP},{ }^{3}[7] \mathrm{CPP}$, and ${ }^{3}[8] \mathrm{CPP}$, respectively).

For the larger macrocycles, the energy differences between the highly symmetric (Baird-aromatic) $\mathrm{T}_{1}$ state structures and the distorted (nonaromatic) ones vary extensively with functional. With UB3LYP, the $C_{4 v}$ and $D_{8 h}$ symmetric structures of ${ }^{3}[8] \mathrm{CPP}$, which are second- and higher-order saddle-points, are merely 2.1 and $3.7 \mathrm{kcal} / \mathrm{mol}$ higher in energy than the unsymmetric one. In contrast, with UM06-2X and UCAM-B3LYP these structures are $22-30 \mathrm{kcal} / \mathrm{mol}$ higher in energy. In the singlet excited states Kim, Nakano, Yamago, and co-workers recently revealed rapid interconversion between self-trapped exciton and delocalized states, ${ }^{90}$ yet it has earlier been found through time-dependent CAM-B3LYP calculations that the $S_{1}$ state of $[n]$ CPP's is more delocalized than the $T_{1}$ state. $^{25}$ Similar observations in the $\mathrm{T}_{1}$ state of various $[n]$ CPP's could give experimental support as to which functional gives the right description: UB3LYP or UCAM-B3LYP?

Now, how to design large $[n]$ CM's (or derivatives) that are Baird-aromatic in their $\mathrm{T}_{1}$ states even with UCAM-B3LYP? To enhance the Baird-aromatic character in ${ }^{3}[n]$ CPP's it should be crucial to reduce the steric congestion between adjacent PP units when aligned. Itami and co-workers recently reported synthesis and further experimental studies of methylenebridged [6]CPP (MB[6] CPP), ${ }^{91}$ a compound that displays magnetically induced paratropic ring currents in the $S_{0}$ state. ${ }^{92}$ We now explored ${ }^{3} \mathrm{MB}[n]$ CPP's with $n=6-8$ using UB3LYP, UM06-2X, and UCAM-B3LYP, and also ${ }^{3} \mathrm{MB}[12] \mathrm{CPP}$ with UCAM-B3LYP. Indeed, with each of the three functionals the ${ }^{3} \mathbf{M B}[n]$ CPP's exhibit fully delocalized yet unevenly distributed $\alpha$-spin density (see Table S9). The HOMA and $\operatorname{NICS}(0)_{z z}$ values of ${ }^{3} \mathrm{MB}[8] \mathrm{CPP}$ with UCAM-B3LYP (0.78 and -40.3 ppm, respectively) clearly reflect Baird-aromatic character. The larger ${ }^{3} \mathbf{M B}[\mathbf{1 2}] \mathbf{C P P}$ calculated with UCAM-B3LYP, however, goes to a structure which similar to ${ }^{3}[\mathbf{1 2}]$ CPP has the spin density distribution localized to a part of the macrocycle and Hückel-aromatic benzene rings in the other part.

The Baird-aromatic character also impacts on the adiabatic $\mathrm{T}_{1}$ energies $\left(E\left(\mathrm{~T}_{1}\right)\right)$ as seen in Table 9. For the Baird-aromatic

Table 9. Adiabatic Triplet State Energies $E\left(T_{1}\right)$ in kcal/ mol $^{a}$

$\begin{array}{lccc}\text { macrocycle } & (\mathrm{U}) \text { B3LYP } & (\mathrm{U}) \text { M06-2X } & \text { (U)CAM-B3LYP } \\ \text { [6]CPP } & 31.5 & 43.5 & 39.1 \\ \text { [7]CPP } & 37.6 & 47.5 & 43.2 \\ \text { [8]CPP } & 42.2 & 52.0 & 46.3 \\ \text { MB[6]CPP } & 34.1 & 46.1 & 43.9 \\ \text { MB[7]CPP } & 39.3 & 50.7 & 47.7 \\ \text { MB[8]CPP } & 42.2 & 60.0 & 62.1 \\ \text { [6]CFU } & 30.5 & 43.0 & 39.0 \\ \text { [7]CFU } & 30.8 & 44.1 & 54.9 \\ \text { [8]CFU } & 28.8 & 41.2 & 37.3\end{array}$

${ }^{a}$ Triplet energies calculated as the absolute free energy differences between the minima in the $S_{0}$ and $T_{1}$ states.

$\mathbf{M B}[n] \mathbf{C P P}$ 's one can note a gradual increase in $E\left(\mathrm{~T}_{1}\right)$ when going from $n=6$ to $n=8$ with each of the three functionals. In contrast, the $E\left(\mathrm{~T}_{1}\right)$ for the unconstrained $[n]$ CPP's, calculated with UM06-2X and UCAM-B3LYP, drop below the ones of the corresponding $\mathbf{M B}[n]$ CPP's, particularly for $n=8$. This indicates that the geometrical relaxation available in the latter, leading to semilocalized triplet diradical character and a few PP units with closed-shell Hückel-aromatic character, providing a stabilization of the $T_{1}$ state with the loss of Baird-aromatic character.

To tailor large unconstrained macrocycles which are Bairdaromatic in $T_{1}$ one may argue that an approach is to utilize $M$ units that can retain Hückel aromaticity in one part of the unit simultaneously as another part is involved in the Bairdaromatic macrocyclic circuit. The 1,4-linked naphthalene could be such a unit, but at UCAM-B3LYP level the [n]cycloparanaphthalenes ( $[n] \mathrm{CN}$ 's) loose Baird-aromatic character already at $n=6$. Steric congestion is likely a contributing factor as the repulsive nonbonded $\mathrm{H}-\mathrm{H}$ interactions should increase in $[n]$ CN's when compared to that in $[n]$ CPP's. Additionally, a Baird-aromatic ${ }^{3}[\mathbf{6}] \mathbf{C N}$ can be described as a triplet state [24]annulene, a species where the lowest energy conformer has a distorted structure with attenuated aromaticity according to UCAM-B3LYP.

Other $M$ units than those based on strongly Hückelaromatic benzene rings are required in order to achieve unconstrained large $[n] \mathbf{C M}$ macrocycles with strong Baird aromaticity. For this aim, it should be favorable to utilize $M$ units that are moderately Hückel-aromatic in $S_{0}$ and/or impose 

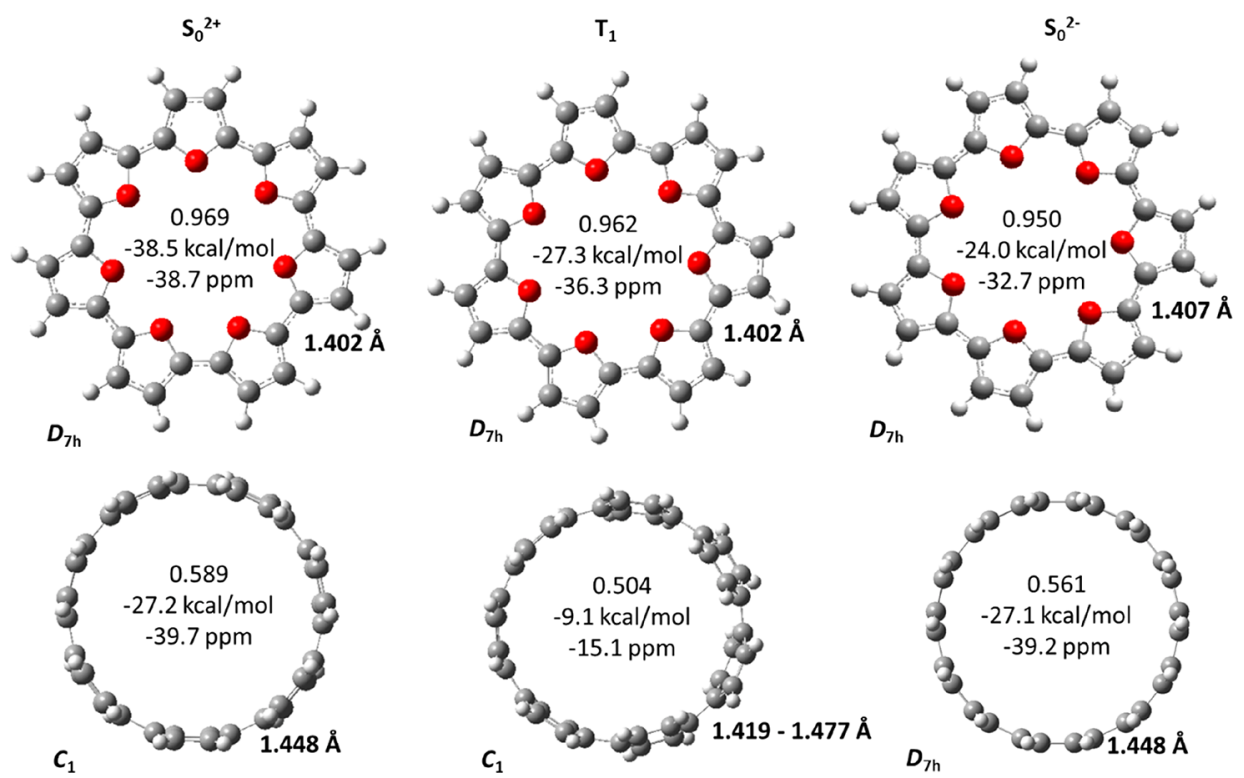

Figure 6. HOMA, ISE and NICS $(0)_{z z}$ values of [7]CFU and [7]CPP in their dicationic and dianionic $\mathrm{S}_{0}$ states and neutral $\mathrm{T}_{1}$ states at (U)B3LYP/ 6-311G $(\mathrm{d}, \mathrm{p})$ and $\mathrm{GIAO} /(\mathrm{U}) \mathrm{B} 3 \mathrm{LYP} / 6-311+\mathrm{G}(\mathrm{d}, \mathrm{p})$ levels. Inter-ring $\mathrm{C}-\mathrm{C}$ bonds in $\AA$ are given below each compound. Symmetries in the optimized geometries are given within each compound.

less steric congestion, and the FU unit is such a unit. Indeed, the ${ }^{3}[6]$ CFU and ${ }^{3}[7]$ CFU macrocycles have clear Bairdaromatic character with all three functionals, and the breakpoint to nonaromatic structures occurs at ${ }^{3}[8]$ CFU. For the latter macrocycle there is just one conformer according to UB3LYP (a Baird-aromatic with $D_{8 h}$ symmetry) but two with UM06-2X and UCAM-B3LYP; the $D_{8 h}$ symmetric conformer and an unsymmetric conformer which are lower in energy by 18.9 and $17.9 \mathrm{kcal} / \mathrm{mol}$, respectively. The unsymmetric conformer of ${ }^{3}[8]$ CFU at UM06-2X and UCAM-B3LYP levels has $\operatorname{NICS}(0)_{z z}$ values that reveal complete lack of aromaticity (-3.2 and $1.7 \mathrm{ppm}$, respectively), and the $\alpha$-spin density is unevenly distributed. Thus, ${ }^{3}[8]$ CFU should likely be considered as nonaromatic despite that the HOMA values with UM06-2X and UCAM-B3LYP (0.81 and 0.78, respectively) are situated within the aromatic range.

Indeed, the existence of a local Baird-aromatic minimum on the $T_{1}$ potential energy surface of ${ }^{3}[8]$ CFU with UB3LYP is interesting as it supports a tug-of-war between a macrocyclic $\mathrm{T}_{1}$ state Baird-aromatic conformer and one conformer having a semilocalized triplet diradical together with one or a few closed-shell Hückel-aromatic FU units. This feature impacts on the $E\left(\mathrm{~T}_{1}\right)$ energies because, similar as for the $[n]$ CPP's, one can note that $\mathrm{T}_{1}$ state Baird-aromatic $[n]$ CFU's have higher $E\left(\mathrm{~T}_{1}\right)$ than the ones with nonaromatic global minima in $\mathrm{T}_{1}$ (Table 9). This feature also points to a pitfall in the explorations of a potentially Baird-aromatic macrocycle as the Baird-aromatic minimum located may not be the global minimum on the $\mathrm{T}_{1}$ PES.

Based on the observation that weakened $S_{0}$ state Hückel aromaticity together with reduced steric congestion brings increased $\mathrm{T}_{1}$ state Baird aromaticity one may ask if changing the PP units in $[n]$ CPP's to either of the three diazines (pyridazine, pyrimidine, and pyrazine) can provide for hetero$[n]$ CPP's which are Baird-aromatic at larger $n$ 's than the allcarbon $[n]$ CPP's? These heterocycles have a lower Hückel aromaticity in $\mathrm{S}_{0}{ }^{26}$ and they are less sterically demanding in nanohoops than the PP unit. ${ }^{93}$ Hence, we explored the hetero- $[n]$ CPP's with UCAM-B3LYP as this functional should underestimate the Baird-aromatic character. Yet, we find that each of the three different hetero- $[n]$ CPP's, $n=6$ and 8 , have unsymmetric global minima in $\mathrm{T}_{1}$ and semilocalized spin densities indicating nonaromatic character. Several of the macrocycles also have Baird-aromatic local minima 12-26 $\mathrm{kcal} / \mathrm{mol}$ higher in energy. Interestingly, some of these higherenergy local minima vanish with UB3LYP and UM06-2X so that only the nonaromatic structures exist with those functionals.

Neutral Macrocycles in $T_{1}$ vs Dicationic and Dianionic Ones in $\mathrm{S}_{0}$. Interesting perspectives on macrocycles with potentially Baird-aromatic $\mathrm{T}_{1}$ states can also be gained through comparisons with the corresponding dications and dianions. Several aromatic $[n] \mathbf{C P P}^{2+}$ have earlier been reported, ${ }^{33,94-97}$ and based on the Zilberg-Haas valence bond description of triplet state aromaticity (Figure $1 \mathrm{~B}$ ), ${ }^{33}$ one may ask to what extent they resemble ${ }^{3}[n]$ CPP's? On the other hand, from a molecular orbital perspective it could be more obvious to compare with the dianions as the same orbitals are occupied. Also the dianions $[n] \mathbf{C P P}^{2-}$ have been explored earlier, and they are aromatic according to computations and have significant quinoidal character in the X-ray crystal structures. ${ }^{34-36}$ Indeed, the dications, dianions, and neutral triplets when viewed with Hückel MO theory all have the same resonance energy as an equal occupancy of the orbitals which are HOMO and LUMO in the neutral $S_{0}$ state will cancel out the contributions from these orbitals according to the Pairing theorem for even alternant hydrocarbons. Thus, the dianion and the neutral triplet should both resemble the dication in terms of resonance stabilization and aromaticity.

The dication [5] $\mathbf{C P P}^{2+}$ in its closed-shell $\mathrm{S}_{0}$ state has a similar NICS value as ${ }^{3}[5]$ CPP (with (U)B3LYP: -41.8 and $-40.5 \mathrm{ppm}$, respectively), and the similarity is underlined by nearly identical HOMA values ( 0.571 and 0.572 , respectively). The dianion [5] $\mathbf{C P P}^{2-}$ has NICS and HOMA values of -38.7 ppm and 0.523, respectively. Yet, the analogy between the three species disappears when going to gradually larger 
[n]CPP's because the dication $[7] \mathbf{C P P}^{2+}$ and dianion [7] $\mathbf{C P P}^{2-}$ with, respectively, 26 and $30 \pi$-electrons in their MCP's, are still Hückel-aromatic whereas the neutral triplet ${ }^{3}$ [7] CPP approaches a nonaromatic situation (Figure 6). The same situation is found with M06-2X. In contrast, the trend is different for the $[7] \mathrm{CFU}^{2+},{ }^{3}[7] \mathrm{CFU}$, and $[7] \mathrm{CFU}^{2-}$ as the degree of aromaticity according to each of the three indices used decreases with number of electrons. One can also see that the inter-ring distance is slightly longer in $[7] \mathrm{CFU}^{2-}$ than in ${ }^{3}[7] \mathrm{CFU}$ and [7] $\mathrm{CFU}^{2+}$. When going to larger [n]CFU's, the ${ }^{3}[n]$ CFU reduces its aromaticity before the corresponding dication and dianion, and the trend is the same with (U)B3LYP and (U)M06-2X when considering NICS and HOMA values.

It is further notable that the inter-ring $\mathrm{CC}$ bonds are shorter in $[7] \mathrm{CFU}^{2+},{ }^{3}[7] \mathrm{CFU}$ and $[7] \mathrm{CFU}^{2-}$ than in the corresponding $[7] \mathbf{C P P}^{2+},{ }^{3}[7] \mathbf{C P P}$, and $[7] \mathbf{C P P}^{2-}$ suggesting stronger macrocyclic aromaticity in the former macrocycle class regardless if dication, neutral triplet, or dianion. The ISE values are, however, high for all [7] CM's except for ${ }^{3}[7]$ CPP. For the latter, the ISE values are much smaller than those of [7] $\mathrm{CPP}^{2+}$, also with UB3LYP, revealing that the macrocyclic Baird aromaticity in the neutral triplet is negligible.

According to both NICS and HOMA at B3LYP and M06$2 \mathrm{X}$ levels, the aromatic character of $[n] \mathbf{C F U}^{2+}$ and $[n] \mathbf{C P P}^{2+}$ diminishes at, respectively, $n>10$ and 12 (Tables S17 and S18), and similar observations are made for the dianions. Indeed, the observation that dicationic macrocycles provide for stronger aromaticity than the neutral $T_{1}$ state is in line with findings made by the Anderson group on the much larger porphyrin nanorings. ${ }^{98}$ For these, magnetically induced diatropic ring-currents were most pronounced in oxidized nanorings having a charge per porphyrin unit in the range $0.5-$ 0.7. In another finding, which similar to that for ${ }^{3}[n]$ CFU and ${ }^{3}[n] \mathbf{C P P}$, a $[n] \mathbf{C F U}^{2+}$ macrocycle is slightly more aromatic than a $[n] \mathbf{C P P}^{2+}$ with the same $n$ according to HOMA, ISE, and FLU while it is the opposite between the two species with NICS (Figure 6 and Tables S17 and S18).

Taken together, the macrocyclic dications $[n] \mathbf{C M}^{2+}$ and dianions $[n] \mathbf{C M}^{2-}$ provide upper limits in $n$ for Baird-aromatic character in the $\mathrm{T}_{1}$ state of a $[n] \mathbf{C M}$. If the macrocyclic dication or dianion, which potentially is readily investigated experimentally, is not Hückel-aromatic, then the analogous neutral triplet will not be Baird-aromatic.

\section{SUMMARY AND OUTLOOK}

Herein we used computational tools to explore a series of macrocycles composed of either benzene, furan, cyclohexa-1,3diene or cyclopentadiene units linked together so that macrocyclic conjugated $4 n \pi$-electron paths are enabled. These macrocycles may all exhibit $\mathrm{T}_{1}$ state Baird-aromatic character, yet, a number of aspects limit the attainment of such character. First, steric congestion distorting the structures away from the ones with maximal macrocyclic $\pi$-conjugation is highly detrimental for $\mathrm{T}_{1}$ state Baird aromaticity. A second factor is the tug-of-war between macrocyclic Baird aromaticity, on the one side, and closed-shell Hückel aromaticity of one or a few $M$ units together with semilocalized tripled diradical character on the remaining $M$ units, on the other. The 2,5linked furan unit (FU) is ideal as it does not induce extensive steric congestion, and it has a lower Hückel-aromatic character in $S_{0}$ than benzene. Hence, regardless of functional used we observe that the $T_{1}$ state Baird aromaticity is less rapidly attenuated in ${ }^{3}[n]$ CFU's than in ${ }^{3}[n]$ CPP's. On the other side, the steric congestion between adjacent PP units in $[n]$ CPP's can be overcome by methylene bridges between the PP units.

The functional used has extensive impact on the breakpoint $n$ at which a $[n]$ CM macrocycle class goes from $\mathrm{T}_{1}$ state Bairdaromatic to nonaromatic character, leading to different breakpoints $n$ at which the $\mathrm{T}_{1}$ structures switch character. Our comparative computations with coupled cluster lead to a provisional preference for UB3LYP geometries, but the trends are similar to the three functionals used. Other functionals may provide different threshold values $n$ (e.g., GGA functionals at somewhat higher $n$ than those here), yet the trend will remain. Here, it should also be stressed that B3LYP is known to overestimate aromaticity of large $\pi$-conjugated cycles in the $S_{0}$ state, $^{82}$ and one should be careful when assessing the degree of triplet state aromaticity of a macrocycle. There is also a variation between different aromaticity indices, although the overall trend is that described above, except for NICS which describes the few ${ }^{3}[n]$ CPP's that are Baird-aromatic to have stronger such character than the analogous ${ }^{3}[n]$ CFU's. Combined, as the choice of functional and aromaticity index, both impact on whether a certain macrocycle is described as triplet state Baird-aromatic or not; one should be cautious in the assessment. As the evaluation of Baird-aromatic character relies heavily on computational results, one should preferably speak of likeliness that a certain macrocycle is Baird-aromatic (or not). There are certainly pitfalls in the area of excited state aromaticity and antiaromaticity.

We also explored the analogy between the neutral triplets and the macrocycle dications, following the valence bond theoretical model by Zilberg and Haas, ${ }^{31}$ and find that the neutral triplets turn nonaromatic at lower $n$ than the dications. Comparisons were also made with the dianions, which in terms of aromaticity resemble the corresponding dications. Hence, if a macrocyclic dication (or dianion) is nonaromatic then the neutral triplet will be as well.

To extrapolate from our findings, we postulate that the tugof-war can tip to the favor of macrocyclic Baird aromaticity if $\pi$-conjugated linkers are inserted between the $M$ units. This also eliminates steric congestion between adjacent $M$ units. A few such molecules have been prepared and explored experimentally. ${ }^{99,100}$ The structurally more complex porphyrinoid macrocycles could also be interesting as the $T_{1}$ state Baird aromaticity in such compounds has been explored extensively. ${ }^{7,13,101-107}$ For the $S_{0}$ state, Aihara and co-workers concluded, based on a graph theoretical analysis, that Hückel's rule is applicable to the main conjugation paths of porphyrinoids having $4 n+2 \pi$-electrons. ${ }^{108-114}$ Yet, the macrocyclic aromaticity in $S_{0}$ was significantly weaker than the aromaticity of the individual monocycles. How does this change in the $T_{1}$ state? These aspects of macrocyclic $T_{1}$ Baird aromaticity will be reported in forthcoming studies.

\section{ASSOCIATED CONTENT}

\section{Supporting Information}

The Supporting Information is available free of charge at https://pubs.acs.org/doi/10.1021/acs.jpca.0c08926.

Details on $T_{1}$ diagnostics and spin contaminations in the DLPNO-CCSD $(T)$ calculations and fractional occupation number weighted density (FOD), relative CASPT2//UDFT energies, and tables and figures with 
geometries, spin densities, ISE, HOMA and NICS $(0)_{\text {iso }}$ values, ACID plots, and Cartesian coordinates and absolute energies (PDF)

\section{AUTHOR INFORMATION}

\section{Corresponding Author}

Henrik Ottosson - Department of Chemistry - Angström Laboratory, Uppsala University, SE-751 20 Uppsala, Sweden; (1) orcid.org/0000-0001-8076-1165;

Email: henrik.ottosson@kemi.uu.se

\section{Authors}

Rabia Ayub - Department of Chemistry - Angström Laboratory, Uppsala University, SE-751 20 Uppsala, Sweden; (1) orcid.org/0000-0003-2128-6733

Ouissam El Bakouri - Department of Chemistry - Ångström Laboratory, Uppsala University, SE-751 20 Uppsala, Sweden; (1) orcid.org/0000-0002-4019-3754

Joshua R. Smith - Department of Chemistry - Angström Laboratory, Uppsala University, SE-751 20 Uppsala, Sweden; Department of Chemistry, Humboldt State University, Arcata, California 95521, United States;

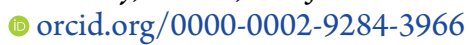

Kjell Jorner - Department of Chemistry - Ångström Laboratory, Uppsala University, SE-751 20 Uppsala, Sweden; (1) orcid.org/0000-0002-4191-6790

Complete contact information is available at: https://pubs.acs.org/10.1021/acs.jpca.0c08926

\section{Notes}

The authors declare no competing financial interest.

\section{ACKNOWLEDGMENTS}

We acknowledge the Erasmus Mundus EXPERTS III program for a graduate student scholarship to R.A, the Wenner-Gren Foundation for a postdoctoral fellowship of O.E.B., and the Swedish Research Council (Grants 2015-04538 and 201905618) for financial support. J.R.S. would like to thank the Swedish Fulbright Commission, the American Scandinavian Foundation, and the HSU College of Natural Resources and Science for supporting his time at UU. The computations were enabled by resources provided by the Swedish National Infrastructure for Computing (SNIC) at the National Supercomputer Center (NSC), Linköping, partially funded by the Swedish Research Council through Grant Agreement Number 2016-07213.

\section{REFERENCES}

(1) Baird, N. C. Quantum Organic Photochemistry. II. Resonance and Aromaticity in the Lowest ${ }^{3} \pi \pi^{*}$ State of Cyclic Hydrocarbons. J. Am. Chem. Soc. 1972, 94, 4941-4948.

(2) Aihara, J.-i. Aromaticity-Based Theory of Pericyclic Reactions. Bull. Chem. Soc. Jpn. 1978, 51, 1788-1792.

(3) Wan, P.; Krogh, E. Evidence for the Generation of Aromatic Cationic Systems in the Excited State. Photochemical Solvolysis of Fluoren-9-ol. J. Chem. Soc., Chem. Commun. 1985, 1207-1208.

(4) Gogonea, V.; Schleyer, P. v. R.; Schreiner, P. R. Consequences of Triplet Aromaticity in $4 \mathrm{n} \pi$-Electron Annulenes: Calculation of Magnetic Shieldings for Open-Shell Species. Angew. Chem., Int. Ed. 1998, 37, 1945-1948.

(5) Ottosson, H. Exciting Excited-State Aromaticity. Nat. Chem. 2012, 4, 969-971.

(6) Rosenberg, M.; Dahlstrand, C.; Kilså, K.; Ottosson, H. Excited State Aromaticity and Antiaromaticity: Opportunities for Photo- physical and Photochemical Rationalizations. Chem. Rev. 2014, 114, 5379-5425.

(7) Oh, J.; Sung, Y. M.; Hong, Y.; Kim, D. Spectroscopic Diagnosis of Excited-State Aromaticity: Capturing Electronic Structures and Conformations upon Aromaticity Reversal. Acc. Chem. Res. 2018, 51, $1349-1358$.

(8) Durbeej, B.; Wang, J.; Oruganti, B. Molecular Photoswitching Aided by Excited-State Aromaticity. ChemPlusChem 2018, 83, 958967.

(9) Liu, C.; Ni, Y.; Lu, X.; Li, G.; Wu, J. Global Aromaticity in Macrocyclic Polyradicaloids: Hückel's Rule or Baird's Rule? Acc. Chem. Res. 2019, 52, 2309-2321.

(10) Karadakov, P. B. Ground- and Excited State Aromaticity and Antiaromaticity in Benzene and Cyclooctatetraene. J. Phys. Chem. A 2008, 112, 7303-7309.

(11) Karadakov, P. B. Aromaticity and Antiaromaticity in the LowLying Electronic States of Cyclooctatetraene. J. Phys. Chem. A 2008, 112, 12707-12713.

(12) Karadakov, P. B.; Hearnshaw, P.; Horner, K. E. Magnetic Shielding, Aromaticity, Antiaromaticity, and Bonding in the LowLying Electronic States of Benzene and Cyclobutadiene. J. Org. Chem. 2016, 81, 11346-11352.

(13) Sung, Y. M.; Yoon, M.-C.; Lim, J. M.; Rath, H.; Naoda, K.; Osuka, A.; Kim, D. Reversal of Hückel (Anti)Aromaticity in the Lowest Triplet States of Hexaphyrins and Spectroscopic Evidence for Baird's Rule. Nat. Chem. 2015, 7, 418-422.

(14) Ueda, M.; Jorner, K.; Sung, Y. M.; Mori, T.; Xiao, Q.; Kim, D.; Ottosson, H.; Aida, T.; Itoh, Y. Energetics of Baird Aromaticity Supported by Inversion of Photoexcited Chiral [4n]Annulene Derivatives. Nat. Commun. 2017, 8, 346.

(15) Hada, M.; Saito, S.; Tanaka, S.; Sato, R.; Yoshimura, M.; Mouri, K.; Matsuo, K.; Yamaguchi, S.; Hara, M.; Hayashi, Y.; et al. Structural Monitoring of the Onset of Excited-State Aromaticity in a Liquid Crystal Phase. J. Am. Chem. Soc. 2017, 139, 15792-15800.

(16) Ayub, R.; Papadakis, R.; Jorner, K.; Zietz, B.; Ottosson, H. Cyclopropyl Group: An Excited-State Aromaticity Indicator. Chem. Eur. J. 2017, 23, 13684-13695.

(17) Ayub, R.; El Bakouri, O.; Jorner, K.; Solà, M.; Ottosson, H. Can Baird's and Clar's Rule Combined Explain Triplet State Energies of Polycyclic Conjugated Hydrocarbons with Fused $4 n \pi$ - and $(4 n+2) \pi$ Rings? J. Org. Chem. 2017, 82, 6327-6340.

(18) Oh, J.; Sung, Y. M.; Mori, H.; Park, S.; Jorner, K.; Ottosson, H.; Lim, M.; Osuka, A.; Kim, D. Unraveling Excited-Singlet-State Aromaticity via Vibrational Analysis. Chem. 2017, 3, 870-880.

(19) Sung, Y. M.; Oh, J.; Kim, W.; Mori, H.; Osuka, A.; Kim, D. Switching between Aromatic and Antiaromatic 1,3-PhenyleneStrapped [26]- and [28]Hexaphyrins upon Passage to the Singlet Excited State. J. Am. Chem. Soc. 2015, 137, 11856-11859.

(20) Peeks, M. D.; Gong, J. Q.; McLoughlin, K.; Kobatake, T.; Haver, R.; Herz, L. M.; Anderson, H. L. Aromaticity and Antiaromaticity in the Excited States of Porphyrin Nanorings. J. Phys. Chem. Lett. 2019, 10, 2017-2022.

(21) Golder, M. R.; Jasti, R. Syntheses of the Smallest Carbon Nanohoops and the Emergence of Unique Physical Phenomena. Acc. Chem. Res. 2015, 48, 557-566.

(22) Darzi, E. R.; Jasti, R. The Dynamic, Size-Dependent Properties of [5] - [12]Cyclopara-phenylenes. Chem. Soc. Rev. 2015, 44, 64016410.

(23) Xu, Y.; von Delius, M. The Supramolecular Chemistry of Strained Carbon Nanohoops. Angew. Chem., Int. Ed. 2020, 59, 559573.

(24) Hermann, M.; Wassy, D.; Esser, B. Conjugated Nanohoops Incorporating Donor-, Acceptor-, Hetero- and Polycyclic Aromatics. Angew. Chem., Int. Ed. 2020, 59.

(25) Liu, J.; Adamska, L.; Doorn, S. K.; Tretiak, S. Singlet and Triplet Excitons and Charge Polarons in Cycloparaphenylenes: A Density Functional Theory Study. Phys. Chem. Chem. Phys. 2015, 17, 14613-14622. 
(26) Dey, S.; Manogaran, D.; Manogaran, S.; Schaefer, H. F., III Quantification of Aromaticity of Heterocyclic Systems Using Interaction Coordinates. J. Phys. Chem. A 2018, 122, 6953-6960.

(27) Mulay, S. V.; Dishi, O.; Fang, Y.; Niazi, M. R.; Shimon, L. J. W.; Perepichka, D. F.; Gidron, O. A Macrocyclic Oligofuran: Synthesis, Solid State Structure and Electronic Properties. Chem. Sci. 2019, 10, 8527-8532.

(28) Dishi, O.; Gidron, O. Macrocyclic Oligofurans: A Computational Study. J. Org. Chem. 2018, 83, 3119-3125.

(29) Wu, J.; Kan, Y.; Xue, Z.; Huang, J.; Chen, P.; Yu, X.; Guo, Z.; $\mathrm{Su}, \mathrm{Z}$. 1,4-Azaborine as Controller of Triplet Energy, Exciton Distribution, and Aromaticity in [6]Cycloparaphenylenes. J. Mater. Chem. C 2017, 5, 9088-9097.

(30) Papadopoulos, A. G.; Charistos, N. D.; Kyriakidou, K.; Sigalas, M. P. Study of Electron Delocalization in 1,2-, 1,3-, and 1,4Azaborines Based on the Canonical Molecular Orbital Contributions to the Induced Magnetic Field and Polyelectron Population Analysis. J. Phys. Chem. A 2015, 119, 10091-10100.

(31) Zilberg, S.; Haas, Y. Two State Model of Antiaromaticity: The Triplet State. Is Hund's Rule Violated? J. Phys. Chem. A 1998, 102, 10851-10859.

(32) Ottosson, H.; Borbas, K. E. A Light-Switched Yin and Yang Pair. Nat. Chem. 2015, 7, 373-375.

(33) Toriumi, N.; Muranaka, A.; Kayahara, E.; Yamago, S.; Uchiyama, M. In-Plane Aromaticity in Cycloparaphenylene Dications: A Magnetic Circular Dichroism and Theoretical Study. J. Am. Chem. Soc. 2015, 137, 82-85.

(34) Taubert, S.; Sundholm, D.; Pichierri, F. Magnetically Induced Currents in [n]Cycloparaphenylenes, $\mathrm{n}=6-11$. J. Org. Chem. 2010, $75,5867-5874$.

(35) Spisak, S. N.; Wei, Z.; Darzi, E.; Jasti, R.; Petrukhina, M. A. Highly Strained [6]Cycloparaphenylene: Crystallization of an Unsolved Polymorph and the First Mono- and Dianions. Chem. Commun. 2018, 54, 7818-7821.

(36) Zhou, Z.; Wei, Z.; Schaub, T. A.; Jasti, R.; Petrukhina, M. A. Structural Deformation and Host-Guest Properties of DoublyReduced Cycloparaphenylenes, $[\mathrm{n}] \mathrm{CPPs}^{2-}(\mathrm{n}=6,8,10$ and 12). Chem. Sci. 2020, 11, 9395-9401.

(37) Bean, D. E.; Fowler, P. E.; Soncini, A. Double Aromaticity and Ring Currents in Open-Shell Systems. Chem. Phys. Lett. 2009, 483, 193-197.

(38) Fowler, P. W.; Mizoguchi, N.; Bean, D. E.; Havenith, R. W. A. Double Aromaticity and Ring Currents in All-Carbon Rings. Chem. Eur. J. 2009, 15, 6964-6972.

(39) Valiev, R. R.; Baryshnikov, G. V.; Nasibullin, R. T.; Sundholm, D.; Ågren, H. When are Antiaromatic Molecules Paramagnetic? J. Phys. Chem. C 2020, 124, 21027-21035.

(40) Charistos, N. D.; Muñoz-Castro, A. Induced Magnetic Field in sp-Hybridized Carbon Rings: Analysis Double Aromaticity and Antiaromaticity in Cyclo[2N]carbon Allotropes. Phys. Chem. Chem. Phys. 2020, 22, 9240-9249.

(41) Dai, C.; Chen, D.; Zhu, J. Achieving Adaptive Aromaticity in Cyclo[10]carbon by Screening Cyclo[n]carbon $(\mathrm{n}=8-24)$. Chem. Asian J. 2020, 15, 2187-2191.

(42) Kaiser, K.; Scriven, L. M.; Schulz, P.; Gawel, P.; Gross, L.; Anderson, H. L. An sp-Hybridized Molecular Carbon Allotrope, Cyclo[18] carbon. Science 2019, 365, 1299-1301.

(43) Scriven, L. M.; Kaiser, K.; Schulz, F.; Sterling, A. J.; Woltering, S. L.; Gawel, P.; Christensen, K. E.; Anderson, H. L.; Gross, L. Synthesis of Cyclo[18]carbon via Debromination of $\mathrm{C}_{18} \mathrm{Br}_{6} . J . A m$. Chem. Soc. 2020, 142, 12921-12924.

(44) Baryshnikov, G. B.; Valiev, R. R.; Kuklin, A. V.; Sundholm, D.; Ågren, H. Cyclo[18]carbon: Insight into Electronic Structure, Aromaticity, and Surface Coupling. J. Phys. Chem. Lett. 2019, 10, 6701-6705

(45) Evans, P. J.; Darzi, E. R.; Jasti, R. Efficient Room-Temperature Synthesis of a Highly Strained Carbon Nanohoop Fragment of Buckminsterfullerene. Nat. Chem. 2014, 6, 404-408.
(46) Zhao, L.; Grande-Aztatzi, R.; Foroutan-Nejad, C.; Ugalde, J. M.; Frenking, G. Aromaticity, the Hückel $4 n+2$ rule and magnetic current. Chemistry Select 2017, 2, 863-870.

(47) Becke, A. D. Density-Functional Thermochemistry. III. The Role of Exact Exchange. J. Chem. Phys. 1993, 98, 5648-5652.

(48) Stephens, P. J.; Devlin, F. J.; Chabalowski, C. F.; Frisch, M. J. $\mathrm{Ab}$ Initio Calculation of Vibrational Absorption and Circular Dichroism Spectra Using Density Functional Force Fields. J. Phys. Chem. 1994, 98, 11623-11627.

(49) Zhao, Y.; Truhlar, D. G. The M06 Suite of Density Functionals for Main Group Thermochemistry, Thermochemical Kinetics, Noncovalent Interactions, Excited States, and Transition Elements: Two New Functionals and Systematic Testing of Four M06-class Functionals and 12 Other Function. Theor. Chem. Acc. 2008, 120, 215-241.

(50) Yanai, T.; Tew, D. P.; Handy, N. C. A New Hybrid ExchangeCorrelation Functional Using the Coulomb-Attenuating Method (CAM-B3LYP). Chem. Phys. Lett. 2004, 393, 51-57.

(51) Krishnan, R.; Binkley, J. S.; Seeger, R.; Pople, J. A. SelfConsistent Molecular Orbital Methods. XX. A Basis Set for Correlated Wave Functions. J. Chem. Phys. 1980, 72, 650-654.

(52) Grimme, S.; Ehrlich, S.; Goerigk, L. Effect of the Damping Function in Dispersion Corrected Density Functional Theory. J. Comput. Chem. 2011, 32, 1456-1465.

(53) Purvis, G. D., III; Bartlett, R. J. A Full Coupled-cluster Singles and Doubles Model: The Inclusion of Disconnected Triples. J. Chem. Phys. 1982, 76, 1910-1918.

(54) Pople, J. A.; Head-Gordon, M.; Raghavachari, K. Quadratic Configuration Interaction. A General Technique for Determining Electron Correlation Energies. J. Chem. Phys. 1987, 87, 5968-5975.

(55) Riplinger, C.; Sandhoefer, B.; Hansen, A.; Neese, F. Natural Triple Excitations in Local Coupled Cluster Calculations with Pair Natural Orbitals. J. Chem. Phys. 2013, 139, 134101.

(56) Riplinger, C.; Neese, F. An Efficient and Near Linear Scaling Pair Natural Orbital Based Local Coupled Cluster Method. J. Chem. Phys. 2013, 138, 034106.

(57) Liakos, D. G.; Neese, F. Is it Possible to Obtain Coupled Cluster Quality Energies at Near Density Functional Theory Cost? Domain-Based Local Pair Natural Orbital Coupled Cluster vs Modern Density Functional Theory. J. Chem. Theory Comput. 2015, 11, 40544063.

(58) Widmark, P.-O.; Persson, B. J.; Roos, B. O. Density Matrix Averaged Atomic Natural Orbital (ANO) Basis Sets for Correlated Molecular Wave Functions. Theor. Chim. Acta 1991, 79, 419-432.

(59) Andersson, K.; Malmqvist, P.-Å.; Roos, B. O. Second-Order Perturbation Theory with a Complete Active Space Self-Consistent Field Reference Function. J. Chem. Phys. 1992, 96, 1218-1226.

(60) Fdez. Galván, I.; Vacher, M.; Alavi, A.; Angeli, C.; Aquilante, F.; Autschbach, J.; Bao, J. J.; Bokarev, S. I.; Bogdanov, N. A.; Carlson, R. K.; et al. Open Molcas: From Source Code to Insight. J. Chem. Theory Comput. 2019, 15, 5925-5964.

(61) Frisch, M. J.; Trucks, G. W.; Schlegel, H. B.; Scuseria, G. E.; Robb, M. A.; Cheeseman, J. R.; Scalmani, G.; Barone, V.; Mennucci, B.; Petersson, G. A.; et al. Gaussian 16; 2016.

(62) Grimme, S.; Hansen, A. A Practical Real-Space Measure and Visualization of Static Electron-Correlation Effects. Angew. Chem., Int. Ed. 2015, 54, 12308-12313.

(63) Neese, F. Software Update: the ORCA Program System, Version 4.0. Wiley Interdiscip. Rev.: Comput. Mol. Sci. 2018, 8, No. e1327.

(64) Schleyer, P. v. R.; Maerker, C.; Dransfeld, A.; Jiao, H.; van Eikema Hommes, N. J. R. Nucleus-Independent Chemical Shifts: A Simple and Efficient Aromaticity Probe. J. Am. Chem. Soc. 1996, 118, 6317-6318.

(65) Fallah-Bagher-Shaidaei, H.; Wannere, C. S.; Corminboeuf, C.; Puchta, R.; Schleyer, P. v. R. Which NICS Aromaticity Index for Planar $\pi$ Rings Is Best? Org. Lett. 2006, 8, 863-866. 
(66) Wolinski, K.; Hinton, J. F.; Pulay, P. Efficient Implementation of the Gauge-Independent Atomic Orbital Method for NMR Chemical Shift Calculations. J. Am. Chem. Soc. 1990, 112, 8251-8260.

(67) Herges, R.; Geuenich, D. Delocalization of Electrons in Molecules. J. Phys. Chem. A 2001, 105, 3214-3220.

(68) Geuenich, D.; Hess, K.; Köhler, F.; Herges, R. Anisotropy of the Induced Current Density (ACID), a General Method to Quantify and Visualize Electronic Delocalization. Chem. Rev. 2005, 105, 37583772 .

(69) Krygowski, T. M. Crystallographic Studies of Inter- and Intramolecular Interactions Reflected in Aromatic Character of KElectron Systems. J. Chem. Inf. Model. 1993, 33, 70-78.

(70) Krygowski, T. M.; Cyranski, M. K. Structural Aspects of Aromaticity. Chem. Rev. 2001, 101, 1385-1419.

(71) Matito, E.; Duran, M.; Solà, M. The Aromatic Fluctuation Index (FLU): A New Aromaticity Index Based on Electron Delocalization. J. Chem. Phys. 2005, 122, 014109. Matito, E.; Duran, M.; Solà, M. J. Erratum: "The aromatic fluctuation index (FLU): A new aromaticity index based on electron delocalization" [J. Chem Phys. 122, 014109 (2005)]. J. Chem. Phys. 2006, 125, 059901.

(72) Zhu, J.; An, K.; Schleyer, P. V. R. Evaluation of Triplet Aromaticity by the Isomerization Stabilization Energy. Org. Lett. 2013, 15, 2442-2445.

(73) Lu, T.; Chen, F. Multiwfn: A Multifunctional Wavefunction Analyzer. J. Comput. Chem. 2012, 33, 580-592.

(74) Matito, E. ESI-3D: Electron Sharing Indexes Program for 3D Molecular Space Partitioning; Institute of Computational Chemistry and Catalysis: Girona, Catalonia, Spain, 2014; http://iqc.udg.es/ eduard/ESIhttp://iqc.udg.es/ eduard/ESI.

(75) AIMAll (Ver. 17.11.14 B); TK Gristmill Software: Overland Park, KS, 2018. http://aim.tkgristmill.com.

(76) Torrent-Sucarrat, M.; Navarro, S.; Cossío, F. P.; Anglada, J. M.; Luis, J. M. Relevance of the DFT Method to Study Expanded Porphyrins with Different Topologies. J. Comput. Chem. 2017, 38, 2819-2828.

(77) Wannere, C. S.; Sattelmeyer, K. W.; Schaefer, H. F.; Schleyer, P. v. R. Aromaticity: The Alternating C-C Bond Length Structures of [14]-, [18]-, and [22]Annulene. Angew. Chem., Int. Ed. 2004, 43, $4200-4206$.

(78) Casademont-Reig, I.; Woller, T.; Contreras-García, J.; Alonso, M.; Torrent-Sucarrat, M.; Matito, E. New Electron Delocalization Tools to Describe the Aromaticity in Porphyrinoids. Phys. Chem. Chem. Phys. 2018, 20, 2787-2796.

(79) Szczepanik, D. W.; Solà, M.; Andrzejak, M.; Pawełek, B.; Dominikowska, J.; Kukułka, M.; Dyduch, K.; Krygowski, T. M.; Szatylowicz, H. The Role of the Long-Range Exchange Corrections in the Description of Electron Delocalization in Aromatic Species. J. Comput. Chem. 2017, 38, 1640-1654.

(80) Sancho-García, J. C. Assessing a New Nonempirical Density Functional: Difficulties in Treating $\pi$-Conjugation Effects. J. Chem. Phys. 2006, 124, 124112.

(81) Sylvetsky, N.; Banerjee, A.; Alonso, M.; Martin, J. M. L. Performance of Localized Coupled Cluster Methods in a Moderately Strong Correlation Regime: Hückel-Möbius Interconversions in Expanded Porphyrins. J. Chem. Theory Comput. 2020, 16, 3641-3653.

(82) Casademont-Reig, I.; Ramos-Cordoba, E.; Torrent-Sucarrat, M.; Matito, E. How Do the Hückel and Baird Rules Fade Away in Annulenes? Molecules 2020, 25, 711.

(83) Tait, C. E.; Neuhaus, P.; Peeks, M. D.; Anderson, H. L.; Timmel, C. R. Transient EPR Reveals Triplet State Delocalization in a Series of Cyclic and Linear $\pi$-Conjugated Porphyrin Oligomers. J. Am. Chem. Soc. 2015, 137, 8284-8293.

(84) Grimme, S.; Antony, J.; Ehrlich, S.; Krieg, H. A Consistent and Accurate $\mathrm{Ab}$ Initio Parametrization of Density Functional Dispersion Correction (DFT-D) for the 94 Elements H-Pu. J. Chem. Phys. 2010, 132, 154104.

(85) Frizzo, C. P.; Martins, M. P. Aromaticity in Heterocycles: New HOMA Index Parametrization. Struct. Chem. 2012, 23, 375-380.
(86) An, K.; Zhu, J. Evaluation of Triplet Aromaticity by the IndeneIsoindene Isomerization Stabilization Energy Method. Eur. J. Org. Chem. 2014, 2014, 2764-2769.

(87) Schleyer, P. v. R.; Pühlhofer, F. Recommendations for the Evaluations of Aromatic Stabilization Energies. Org. Lett. 2002, 4, 2873-2876.

(88) Gershoni-Poranne, R.; Stanger, A. Magnetic Criteria of Aromaticity. Chem. Soc. Rev. 2015, 44, 6597-6615.

(89) Van Damme, S.; Acke, G.; Havenith, R. W.; Bultinck, P. Can the Current Density Map Topology be Extracted from the Nucleus Independent Chemical Shift? Phys. Chem. Chem. Phys. 2016, 18, 11746-11755.

(90) Kim, J.; Kishi, R.; Kayahara, E.; Kim, W.; Yamago, S.; Nakano, M.; Kim, D. Ultrafast Exciton Self-Trapping and Delocalization in Cycloparaphenylenes: The Role of Excited-State Symmetry in Electron-Vibrational Coupling. Angew. Chem., Int. Ed. 2020, 59, 16989-16996.

(91) Li, Y.; Segawa, Y.; Yagi, A.; Itami, K. A Nonalternant Aromatic Belt: Methylene-Bridged [6]Cycloparaphenylene Synthesized from Pillar[6] arene. J. Am. Chem. Soc. 2020, 142, 12850-12856.

(92) Summa, F. F.; Monaco, G.; Scott, L. T.; Zanasi, R. Disentangling the Contributions to Proton Magnetic Shielding in Carbon Nanohoops and Nanobelts: Evidence for a Paratropic BeltCurrent. J. Phys. Chem. Lett. 2020, 11, 7489-7494.

(93) Bachrach, S. M.; Stück, D. DFT Study of Cycloparaphenylenes and Heteroatom-Substituted Nanohoops. J. Org. Chem. 2010, 75, $6595-6604$.

(94) Alvarez, M. P.; Ruiz Delgado, M. C.; Taravillo, M.; Baonza, V. G.; Lopez Navarrete, J. T.; Evans, P.; Jasti, R.; Yamago, S.; Kertesz, M.; Casado, J. The Raman Fingerprint of Cyclic Conjugation: The Case of the Stabilization of Cations and Dications in Cycloparaphenylenes. Chem. Sci. 2016, 7, 3494-3499.

(95) Kayahara, E.; Fukayama, K.; Nishinaga, T.; Yamago, Y. Size Dependence of $[\mathrm{n}]$ Cyclo-paraphenylenes $(\mathrm{n}=5-12)$ in Electrochemical Oxidation. Chem. - Asian J. 2016, 11, 1793-1797.

(96) Fujitsuka, M.; Kayahara, E.; Lu, C.; Yamago, S.; Majima, T. Significant Structural Relaxations of Excited [n]Cycloparaphenylene Dications ( $\mathrm{n}=5-9)$. Phys. Chem. Chem. Phys. 2018, 20, 2920729211.

(97) Masumoto, Y.; Toriumi, N.; Muranaka, A.; Kayahara, E.; Yamago, S.; Uchiyama, M. Near-Infrared Fluorescence from In-PlaneAromatic Cycloparaphenylene Dications. J. Phys. Chem. A 2018, 122, 5162-5167.

(98) Peeks, M. D.; Tait, C. E.; Neuhaus, P.; Fischer, G. M.; Hoffmann, M.; Haver, R.; Cnossen, A.; Harmer, J. R.; Timmel, C. R.; Anderson, H. L. Electronic Delocalization in the Radical Cations of Porphyrin Oligomer Molecular Wires. J. Am. Chem. Soc. 2017, 139, 10461-10471.

(99) Kawase, T.; Darabi, H. R.; Oda, M. Cyclic [6]- and [8]Paraphenylacetylenes. Angew. Chem., Int. Ed. Engl. 1996, 35, 2664-2626.

(100) Ohkita, M.; Ando, K.; Tsuji, T. Synthesis and Characterization of [46] Paracyclophano-decayne Derivative. Chem. Commun. 2001, $2570-2571$

(101) Kim, J.; Oh, J.; Soya, T.; Yoneda, T.; Park, S.; Lim, M.; Osuka, A.; Kim, D. Excited-State Aromaticity of Gold(III) Hexaphyrins and Metalation Effect Investigated by Time-Resolved Electronic and Vibrational Spectroscopy. Angew. Chem., Int. Ed. 2020, 59, 51295134.

(102) Izawa, M.; Kim, T.; Ishida, S.; Tanaka, T.; Mori, T.; Kim, D.; Osuka, A. Möbius Aromatic [28] Hexaphyrin Germanium(IV) and Tin(IV) Complexes: Efficient Formation of Triplet Excited States. Angew. Chem., Int. Ed. 2017, 56, 3982-3986.

(103) Oh, J.; Sung, Y. M.; Kim, W.; Mori, S.; Osuka, A.; Kim, D. Aromaticity Reversal in the Lowest Excited Triplet State of Archetypical Möbius Heteroannulenic Systems. Angew. Chem., Int. Ed. 2016, 55, 6487-6491.

(104) Sung, Y. M.; Oh, J.; Naoda, K.; Lee, T.; Kim, W.; Lim, M.; Osuka, A.; Kim, D. A Description of Vibrational Modes in 
Hexaphyrins: Understanding the Aromaticity Reversal in the Lowest Triplet State. Angew. Chem., Int. Ed. 2016, 55, 11930-11934.

(105) Hong, Y.; Oh, J.; Sung, Y. M.; Tanaka, Y.; Osuka, A.; Kim, D. The Extension of Baird's Rule to Twisted Heteroannulenes: Aromaticity Reversal of Singly and Doubly Twisted Molecular Systems in the Lowest Triplet State. Angew. Chem., Int. Ed. 2017, 56, 2932-2936.

(106) Cha, W.-Y.; Kim, T.; Ghosh, A.; Zhang, Z.; Ke, X.-S.; Ali, R.; Lynch, V. M.; Jung, J.; Kim, W.; Lee, S.; Fukuzumi, S.; Park, J. S.; Sessler, J. L.; Chandrashekar, T. K.; Kim, D. Bicyclic Baird-type Aromaticity. Nat. Chem. 2017, 9, 1243-1248.

(107) Valiev, R. R.; Fliegl, H.; Sundholm, D. Bicycloaromaticity and Baird-type Bicycloaromaticity of Dithienothiophene-Bridged [34]Octaphyrins. Phys. Chem. Chem. Phys. 2018, 20, 17705-17713.

(108) Aihara, J-i Graph Theory of Aromatic Stabilization. Bull. Chem. Soc. Jpn. 2016, 89, 1425-1454.

(109) Aihara, J-i.; Makino, M.; Ishida, T.; Dias, J. R. Analytical Study of Superaromaticity in Cycloarenes and Related Coronoid Hydrocarbons. J. Phys. Chem. A 2013, 117, 4688-4697.

(110) Aihara, J-i.; Makino, M.; Sakamoto, K. Superaromatic Stabilization Energy as a Novel Local Aromaticity Index for Polycyclic Aromatic Hydrocarbons. J. Phys. Chem. A 2013, 117, 10477-10488.

(111) Makino, M.; Aihara, J-i. Macrocyclic Aromaticity of Porphyrin Units in Fully Conjugated Oligoporphyrins. J. Phys. Chem. A 2012, 116, 8074-8084.

(112) Aihara, J-i.; Nakagami, Y.; Sekine, R.; Makino, M. Validity and Limitations of the Bridged Annulene Model for Porphyrins. J. Phys. Chem. A 2012, 116, 11718-11730.

(113) Aihara, J-i.; Makino, M. Prediction of the Main Macrocyclic Conjugation Pathways for Porphyrinoids from the Ring Current Distribution. Org. Biomol. Chem. 2010, 8, 261-266.

(114) Aihara, J-i.; Horibe, H. Macrocyclic Aromaticity in Hückel and Möbius Conformers of Porphyrinoids. Org. Biomol. Chem. 2009, 7, 1939-1943. 